Max-Planck-Institut für demografische Forschung

Max Planck Institute for Demographic Research

Konrad-Zuse-Strasse 1 - D-18057 Rostock - GERMANY

Tel +49 (0) 3812081 - 0; Fax +49 (0) 3812081 - 202;

http://www.demogr.mpg.de

MPIDR WORKING PAPER WP 2013-012

SEPTEMBER 2013

\title{
To give or not to give:
}

bequest estimate and wealth impact

based on a CGE model with realistic demography in Japan

\author{
Miguel Sánchez-Romero (msanchez@demogr.mpg.de) \\ Naohiro Ogawa \\ Rikiya Matsukura
}

This working paper has been approved for release by: Michaela Kreyenfeld (kreyenfeld@demogr.mpg.de), Deputy Head of the Laboratory of Economic and Social Demography.

(C) Copyright is held by the authors.

Working papers of the Max Planck Institute for Demographic Research receive only limited review. Views or opinions expressed in working papers are attributable to the authors and do not necessarily reflect those of the Institute. 


\title{
To give or not to give a bequest: Bequest estimate and wealth impact based on a CGE model with realistic demography in Japan*
}

\author{
Miguel Sánchez-Romero ${ }^{1}$
}

\author{
Naohiro Ogawa ${ }^{2}$ \\ Rikiya Matsukura² \\ ${ }^{1}$ Max Planck Institute for Demographic Research \\ Rostock, Germany \\ ${ }^{2}$ Population Research Institute, Nihon University \\ Tokyo, Japan
}

\begin{abstract}
In Japan due to the rapid population aging and its large financial pressure on pay-as-you-go retirement systems, the economic impact of bequest wealth has been drawing a tremendous amount of attention. Despite that, there are neither official statistics on bequest for the whole population, nor analyses of the historical evolution of bequest. Our study fills this gap by offering an estimate of bequest in Japan from 1850 to 2100 , based on a computable general equilibrium model with realistic demography. Our model shows that the historical evolution of the bequest-to-output ratio in Japan follows the same U-shaped pattern described by Piketty (2011) for France. Moreover, we estimate that the annual flow of bequest represented between $4 \%$ and $6 \%$ of the output in the year 2000 and that it will reach between $7 \%$ and $13 \%$ of the output by year 2100 .
\end{abstract}

\section{Introduction}

Historically, economic development in most countries has been accompanied by a decline in the total fertility rate, increase in life expectancy, especially at older ages, and population aging. These changes tend to affect a country's economic growth, saving rates, and worker productivity. Moreover, these demographic

\footnotetext{
*The authors are grateful to seminar participants at Nihon University Population Research Institute, the 9th meeting of the Working Group on Macroeconomic Aspects of Intergenerational Transfers (UB, Barcelona), and IUSSP 2013 for helpful comments. We have benefited from comments, suggestions, and ideas of Ronald Lee, Andrew Mason, Hidehiko Ichimura, and we also have received useful assistance from Junichi Sakamoto. Of course, any possible errors are our own.
} 
trends place a large financial pressure on pay-as-you-go retirement systems, and impose a heavy burden on young and unborn cohorts. For this reason, it is essential for policymakers to find new resources that can reduce negative economic consequences of population aging and maintain an intergenerational equilibrium.

An obvious candidate is the amount of wealth that is transferred to surviving individuals at death, i.e. bequest. In modern economies, economic growth comes from the accumulation of human and non-human capital. Unless the technological progress is high, rapid population aging leads to an inevitable decline in the accumulation of human capital. In contrast, assets can be passed from one generation to another. Also, assets can be used by one cohort to compensate for the increasing fiscal burden of subsequent cohorts.

In this regard, Japan is an interesting and special case because it's population aging has been the fastest in the world, and yet the labor force participation rates for older persons also remain among the highest among developed countries. Furthermore, in Japan, which is comparatively advanced in terms of policies regarding population aging, the economic impact of bequest wealth has been drawing a tremendous amount of attention. And yet, despite that, there are neither official statistics on bequest for the whole population nor analyses of its historical evolution.

Our study aims to fill this gap by offering an estimate of bequest in Japan from 1850 to 2100 , based on a computable general equilibrium model (CGE) with realistic demography. Specifically, we create an economic model based on a real-life population structure, in which consumption/saving, labor supply (at the intensive and extensive margins), and bequest are determined endogenously. Furthermore, we demonstrate our model's traceability by comparing our bequest profiles to real bequest values obtained from the Japanese Study on Aging and Retirement (JSTAR) and consumption and labor profiles from the National Transfer Accounts (NTA) project.

Since in the past there were no surveys that asked about the amount of bequests that respondents received, previous studies have implemented different methods to overcome this problem. For example, following Kotlikoff and Summers (1981), Hayashi (1986), Dekle (1989), and Campbell (1997) calculated the bequest amount by deducting lifecycle wealth from household wealth. Barthold and Ito (1992) did an inverse calculation of the amount of taxable bequests based on inheritance tax statistics, while Shimono (1991) conducted a simulation analysis, and Shimono and Ishikawa (2002) estimated the proportion of bequests based on the scenario that males 65 and over die immediately. The downside of estimating bequest from the Japanese National Tax Agency's data is that there are a lot of cases of tax exemption. In this paper, instead, we estimate the bequest amount using JSTAR. Its database provides panel data on individuals between ages 50 to 75 in year 2007. Importantly, JSTAR is similar to the Health and Retirement Study (HRS), the English Longitudinal Survey on Ageing (ELSA), and the Survey on Health, Aging and Retirement in Europe (SHARE). Hence, JSTAR contains a variety of variables comparable to those in the HRS, ELSA, and SHARE (Ichimura et al., 2009). By using JSTAR we are able to estimate the bequest received between year 2007 and 2009. Unfortunately, the sample of people who received bequest during the first two waves of this survey is only 216 cases out of 3946 . Consequently, we have opted for running three alternative scenarios that we believe cover the most likely bequest 
profile for the reference year 2009.

The results obtained from our simulations show that the historical evolution of the bequest-to-output ratio follows the same U-shaped pattern as described by Piketty (2011) for France. However, the most important component explaining the U-shaped pattern is the evolution of the crude death rate (i.e. the number of deaths relative to the total population during a given year), rather than the evolution of the capital-to-output ratio or the ratio between the average wealth of the deceased and the average wealth of the living. Second, we estimate that in the year 2000 the annual flow of bequest accounted between $4 \%$ and $6 \%$ of the output and that it would reach between $7 \%$ and $13 \%$ of the output by year 2100 . Hence, if the current bequest represents $50 \%$ of the total inheritance as in France, the share of the annual flow of inheritance in the GDP is likely to be over $10 \%$ in present day Japan. Our simulation results show that during the 21st century the influence of bequest and labor income in shaping the accumulation of assets will be the same as in the second half of the 20th century, unless individuals' bequest motives strengthen.

The rest of the paper is organized as follows: Section 2 introduces the economic and demographic model setup. In Section 3 we present the economic and demographic data used to perform the calibration process. Also, we demonstrate that our model reproduces well the historical evolution of the capital-to-output ratio, consumption profiles, and labor income profiles for several years, as well as the per capita bequest by age in year 2009. In Section 4 we report on our estimated evolution of the bequest from year 1850 to 2100 . Section 5 is devoted to showing the distribution of per capita bequest during the period 1850-2100 and demonstrating the relationship between the distribution of bequest by age and the capital stock. Concluding remarks are made in Section 6.

\section{Model economy}

\subsection{Demographics}

Time is discrete. Let $t \in \mathcal{T}=\left\{t_{0}, t_{0}+1, \ldots, T\right\}$ denote time, where $t_{0}$ and $T$ are the first and last years at which the population is computed. Individuals face mortality and fertility risk that differs by age and across cohorts. Lifetime uncertainty is represented by a standard survival probability function $s_{i, x}$. Let $p_{i, x}$ be the conditional probability of surviving to age $x+1$ of an individual born in year $i$ (with $p_{i, x}=0$ for all $x=\Omega$, where $\Omega$ is the maximum age), and let $q_{i, x}=1-p_{i, x}$ be the conditional probability of dying between age $x$ and $x+1$. The probability that an individual born in year $i$ survives at least to age $x$, conditional on being alive at age 0 , is given by:

$$
s_{i, x}=\prod_{u=0}^{x-1} p_{i, u}, \text { where } p_{i, 0}=1 .
$$

Let $N_{t}$ denote the total population size in year $t$ and $N_{t, x}$ be the size of the population at age $x$ in year $t$. We assume a closed population whose law of motion is given by

$$
N_{t+1}=N_{t}+B_{t}-D_{t} .
$$

Population in year $t+1$ equals the population in year $t$ plus the total number of births in year $t$, denoted by $B_{t}$, minus the total number of deaths during 
the year $t$, or $D_{t}$. The dynamics of the population can also be expressed as a first-order Markov process using the Leslie matrix (Leslie, 1945):

$$
\mathcal{N}(t+1)=\mathcal{L}(t) \mathcal{N}(t),
$$

where $\mathcal{N}(t)$ is a $\Omega \times 1$ vector that contains the population size by age in year $t$. $\mathcal{L}$ is a matrix with structural zeros, except for the first row that contains the expected number of children at the end of the period, i.e. $\mathcal{L}_{1, x}(t)=$ $\frac{1}{2}\left(f_{t-x, x}+f_{t-x-1, x+1} p_{t-x, x}\right) f_{f a b}$, where $f_{t-x, x}$ is the age-specific fertility rate at age $x$ of an individual born in year $t-x$ and $f_{f a b}$ is the standard value of the fraction of females at birth $\left(f_{f a b}=0.4886\right)$, and the first sub-diagonal that contains the conditional survival probabilities, i.e. $\mathcal{L}_{x+1, x}(t)=p_{t-x, x}$.

In our model households are comprised of two adults, or household heads, and dependent children. Notice that this assumption is necessary for a realistic distribution of bequest between offspring and the surviving spouse. For the sake of simplicity, we introduce the following demographic assumptions: i) individuals are paired at the onset of fertility with people of the same cohort ("married"); ii) exit from "marriage" only occurs because of death ("widowhood"); iii) bequest is given either to the children, or the spouse, or both; iv) children have two representative parents; and v) the burden of rearing children is equally distributed between both household heads, where child rearing is seen as a commitment of time and money by parents for the purpose of supporting their children's consumption needs. Based on assumptions i) and ii), we can characterize the partnership status of an individual born in year $t$ and age $x$ according to a Markovian process of order one:

$$
\left(\begin{array}{c}
m_{i, x+1} \\
h_{i, x+1} \\
d_{i, x+1}
\end{array}\right)=\left(\begin{array}{ccc}
p_{i, x} q_{i, x} & 0 & 0 \\
2 q_{i, x} p_{i, x} & p_{i, x} & 0 \\
q_{i, x} q_{i, x} & q_{i, x} & 1
\end{array}\right) \cdot\left(\begin{array}{c}
m_{i, x} \\
h_{i, x} \\
d_{i, x}
\end{array}\right),
$$

where $m_{i, x}$ is the probability that both heads are married at age $x, h_{i, x}$ is the probability that one head is a widow/er at age $x$, and $d_{i, x}$ is the probability that both heads are dead at age $x$. The total time devoted to childrearing for a household head born in year $i$ at age $x$ is represented by $\eta_{i, x}^{\ell} \geq 0$. The size of the household for each household head $\eta_{i, x}^{c} \geq 1$, which is expressed in units of equivalent adult consumers, takes into account the cost of the consumption needs of the children. Let $\boldsymbol{\eta}_{i, x}=\left\{\eta_{i, x}^{c}, \eta_{i, x}^{\ell}\right\}$ be the set of both burden variables, which varies over time because of fertility and mortality and because children leave their parents'.

\section{$2.2 \quad$ Firm}

We adopt a neoclassical representative firm that combines capital and labor using the Cobb-Douglas constant returns to scale production function to produce a single good, which can either be saved or consumed,

$$
Y_{t}=K_{t}^{\alpha}\left(\Gamma_{t} L_{t}\right)^{1-\alpha},
$$

where $Y_{t}$ is output, $K_{t}$ is the stock of capital, $\alpha$ is the capital share, $L_{t}$ is the effective aggregate labor input, and $\Gamma_{t}$ is labor-augmenting technological 
progress, whose law of motion is $\Gamma_{t+1}=\left(1+g_{t}\right) \Gamma_{t}$. Aggregate capital stock evolves according to the law of motion:

$$
K_{t+1}=K_{t}(1-\delta)+I_{t},
$$

where $\delta$ is the depreciation rate of capital and $I_{t}$ is aggregate gross investment.

We assume that our representative firm maximizes the net cash flow by renting capital and hiring labor from households in competitive markets at the rates $r$ and $w$, respectively. We also assume that capital and skill-specific labor inputs are chosen by firms according to the first-order conditions:

$$
\begin{aligned}
r_{t}+\delta & =\alpha\left(Y_{t} / K_{t}\right), \\
\left(1+(1-\varsigma) \tau_{s, t}\right) w_{t} & =(1-\alpha)\left(Y_{t} / L_{t}\right) .
\end{aligned}
$$

where $(1-\varsigma) \tau_{s, t}$ reflects the fraction of the social contribution paid by the employer.

\subsection{Household's problem}

Households are comprised of either one adult ("widow/er") or two adults ("marriage"), and a number of dependent children. Household heads equally share the duties and benefits of the household. Individuals become adults at age 20 $x_{0}$, the moment at which they become financially independent and set up their own household.

Furthermore we assume that adults follow the life-cycle theory of labor supply (Heckman and MaCurdy, 1980, 1982) under mortality risks (Yaari, 1965), make endogenous retirement decision (Sanchez-Romero et al., 2013), and have bequest motives (Imrohoroglu and Kitao, 2012). The conditional expected utility function on retiring at age $z$ for a household head born in year $i$ at age $x$ is

$$
V\left(a_{i, x_{0}} ; z\right)=\sum_{x=x_{0}}^{\Omega-1}\left(\prod_{s=x_{0}}^{x} \beta p_{i, s}\right) \frac{u\left(c_{i, x}, \ell_{i, x}\right)+\beta q_{i, x+1} u^{B}\left(a_{i, x+1}\right)}{\beta p_{i, x_{0}}},
$$

where $\beta$ is the subjective discount factor, $u$ is the period utility function (with $u_{c} \geq 0, u_{\ell} \leq 0, u_{c \ell} \geq 0$, and $\left.u_{c c}, u_{\ell \ell} \leq 0\right), c_{i, x}$ is the consumption cost bore by one household head, and $\ell_{i, x}$ is the work effort of an adult born in year $i$ of age $x, u^{B}$ is the period utility from leaving bequest (with $u_{a}^{B} \geq 0, u_{a a}^{B} \leq 0$ ), and $a_{i, x}$ are asset holdings at age $x$.

Adults start with zero assets (i.e. $a_{i, x_{0}}=0$ ) and their borrowing is constrained (i.e. $a_{i, x} \geq 0$ ). The gross labor income at age $x$ depends on the age-specific productivity $\epsilon_{x}$, the aggregate wage per efficiency unit $w_{i+x}$, and the work effort $\ell_{i, x}$. Assets held evolves over the life cycle according to

$$
\begin{gathered}
a_{i, x+1}= \\
\begin{cases}R_{i+x}^{a} a_{i, x}+R_{i+x}^{b} B e q_{i, x}+\left(1-\tau_{l}-\varsigma \tau_{s, i+x}\right) w_{i+x} \epsilon_{x} \ell_{i, x}-\left(1+\tau_{c, i+x}\right) c_{i, x} & \text { if } x_{0} \leq x<z, \\
R_{i+x}^{a} a_{i, x}+R_{i+x}^{b} B e q_{i, x}+b_{i, x}(z)-\left(1+\tau_{c, i+x}\right) c_{i, x} & \text { if } z \leq x<\Omega .\end{cases}
\end{gathered}
$$

where $R_{i+x}^{a}=\left(1+r_{i+x}\left(1-\tau_{k}\right)\right)\left(1+\gamma \frac{q_{i, x}}{p_{i, x}}\right)-\tau_{p}$ is the after-tax compound interest rate contingent on annuitizing a fraction $\gamma$ of assets held, $R_{i+x}^{b}=$ 
$1+r_{i+x}\left(1-\tau_{k}\right)-\tau_{b}$ is the after-tax compound interest rate on bequest, $B e q_{i, x}$ is the bequest received at age $x,\left\{\tau_{k}, \tau_{l}, \tau_{p}, \tau_{b}, \tau_{c}, \tau_{s}.\right\}$ are the taxes on capital income, labor income, property, bequest, consumption, and social contribution, respectively, with $\varsigma$ being the fraction of social contributions paid by the employee, and $b_{i, x}(z)$ is the conditional pension benefit on retirement at age $z$ earned at age $x$.

Similar to the Japanese pension system, we assume that pension benefits consist of a full basic pension, $b_{i, x}^{k n}(z)$, and an earning-related pension, $b_{i, x}^{e}(z)$. Assuming that the person provides labor all throughout his/her lifecycle, we calculate the pension benefit that our individual claims according to the following formula:

$$
b_{i, x}(z) \equiv b_{i, x}^{k n}(z)+b_{i, x}^{e}(z)=\lambda(z) \mu \bar{\omega}_{i+z}+\vartheta_{i+x} \frac{\psi(z)}{N_{b}} \sum_{u=z-N_{b}}^{z-1} w_{i+u} \epsilon_{u} \ell_{i, u}
$$

where $\lambda(z)$ denotes the penalties and incentives for early and late retirement

$$
\lambda(z)= \begin{cases}1+\lambda_{p}\left(z-z_{n}\right) & \text { if } z<z_{n} \\ 1+\lambda_{r}\left(z-z_{n}\right) & \text { if } z \geq z_{n}\end{cases}
$$

where $\left\{\lambda_{p}, \lambda_{r}\right\}$ are the annual penalty and reward rates, respectively, and $z_{n}$ is the normal retirement age, $\mu$ is the basic pension benefits to average labor income ratio, $\bar{\omega}_{t}$ is the average earnings in year $t, \vartheta_{t}$ is the value of the automatic adjustment factor mechanism in year $t$ introduced to guarantee the sustainability of the public pension scheme, $N_{b}$ is the assessment period and $\psi(z)$, which is equal to $r_{a} \cdot z$, is the accumulated accrual rate of the pension benefit, where $r_{a}$ is the annual accrual rate.

\subsection{Household heads' optimal decisions}

Conditional on the retirement age $z$, we calculate the household head's optimal decision recursively using backward induction from age $\Omega$ until age $x_{0}$. The Bellman equation of a household head born in year $i$ at age $x$ is

$$
\begin{aligned}
V\left(a_{i, x} ; z\right)=\max _{c_{i, x}, \ell_{i, x}}\left\{u\left(c_{i, x}, \ell_{i, x} ; \boldsymbol{\eta}_{i, x}\right)\right. & \\
& \left.+\beta\left(p_{i, x+1} V\left(a_{i, x+1} ; z\right)+q_{i, x+1} u^{B}\left(a_{i, x+1}\right)\right)\right\}
\end{aligned}
$$

subject to (10). The first-order conditions on consumption and work for the household head effort are:

$$
\begin{aligned}
\frac{-u_{\ell}\left(c_{i, x}, \ell_{i, x} ; \boldsymbol{\eta}_{i, x}\right)}{u_{c}\left(c_{i, x}, \ell_{i, x} ; \boldsymbol{\eta}_{i, x}\right)} & =w_{i+x} \epsilon_{x}\left(1-t_{i, x}^{E}\right) \\
\frac{u_{c}\left(c_{i, x}, \ell_{i, x} ; \boldsymbol{\eta}_{i, x}\right)}{u_{c}\left(c_{i, x+1}, \ell_{i, x+1} ; \boldsymbol{\eta}_{i, x+1}\right)} & =\frac{\beta R_{i+x+1}^{a} p_{i, x+1}\left(1+\tau_{c x}\right)}{1+\tau_{c x+1}} \\
& +\frac{R_{i+x+1}^{a} q_{i, x+1}\left(1+\tau_{c x}\right) u_{a}^{B}\left(a_{i, x+1}\right)}{u_{c}\left(c_{i, x+1}, \ell_{i, x+1} ; \boldsymbol{\eta}_{i, x+1}\right)}
\end{aligned}
$$

where $1-t_{i, x}^{E}=\frac{1-\tau_{l}-\varsigma \tau_{s, i+x}}{1+\tau_{c x}}$ is the effective labor income tax of an individual born in year $i$ at age $x$. Eq. 14 means that the marginal rate of substitution 
between leisure and consumption equals the wage rate net of effective labor income tax. Under the current model, Eq. 15 shows that the marginal rate of substitution between present and future consumption increases not only because of the factor $\beta R_{i+x+1}^{a} p_{i, x+1}$ but also with higher values of the marginal utility from leaving a bequest.

The optimal retirement age condition is:

$$
\begin{array}{r}
{\left[u_{c}\left(c_{i, z^{*}}, \ell_{i, z^{*}} ; \boldsymbol{\eta}_{i, z^{*}}\right)-\beta q_{i, z^{*}+1} u_{a}^{B}\left(a_{i, z^{*}+1}\right)\left(1+\tau_{c, z^{*}}\right)\right] w_{i+z^{*}} \epsilon_{z^{*}} \ell_{i, z^{*}}\left(1-t_{i, z^{*}}^{P}\right)} \\
=u\left(c_{i, z^{*}}, 0 ; \boldsymbol{\eta}_{i, z^{*}}\right)-u\left(c_{i, z^{*}}, \ell_{i, z^{*}} ; \boldsymbol{\eta}_{i, z^{*}}\right) .
\end{array}
$$

where $t_{i, x}^{P}=\frac{1-\tau_{l}-t_{i, x}^{G W}}{1+\tau_{c x}}$ is the effective participation tax, and $t_{i, x}^{G W}$ is the tax/subsidy rate introduced by Gruber and Wise (1999, 2004, 2007). Eq. 16 shows that individuals optimally retire when the marginal benefit of continuing to work at age $z^{*}$ (left-hand side) equals the marginal cost of working (right-hand side). Notice that, ceteris paribus, the marginal utility of leaving a bequest (the second term in brackets) affects the retirement decision negatively through a reduction in the marginal benefit of working. Besides, since continued work at older ages does not seem to increase the household head's cost, under the current model the retirement decision is primarily explained by retirement incentives (Gruber and Wise, 1999).

\subsection{Government}

The government runs a two-tier PAYG pension scheme: a basic pension and an earnings-related pension. The total cost of each pension scheme in year $t$ is:

$$
\begin{aligned}
\mathrm{BP}_{t} & =\sum_{x=z_{e}}^{\Omega-1} b_{t-x, x}^{k n}(z) N_{t-x, x+1}, & & \text { (Basic pension) } \\
\mathrm{EP}_{t} & =\sum_{x=z_{e}}^{\Omega-1} b_{t-x, x}^{e}(z) N_{t-x, x+1} . & & \text { (Employee's pension) }
\end{aligned}
$$

Each pension scheme follows a different financing mechanism. In particular, a fraction $\theta_{t}$ of the total basic pensions claimed in year $t\left(\mathrm{BP}_{t}\right)$ is financed through contributions, whereas a fraction $1-\theta_{t}$ is financed through general taxes. In contrast, the Employee's Pension Scheme was originally designed to be fully funded by current contributions. Since the 2004 reform, the future evolution of the social contribution tax rate is capped and an automatic sustainability factor mechanism based on the active population and life expectancy from age 65 has been implemented, $\vartheta_{t}$. Hence, we assume that any temporary difference between $\mathrm{EP}_{t}$ and contributions received will be financed through general taxes. The social contribution rate satisfies the following:

$$
\begin{aligned}
& \tau_{s, t}^{k n} \sum_{x=x_{0}}^{z-1} w_{t} \epsilon_{x} \ell_{t-x, x} N_{t-x, x+1}=\theta_{t} \mathrm{BP}_{t}, \\
& \tau_{s, t}^{e} \sum_{x=x_{0}}^{z-1} w_{t} \epsilon_{x} \ell_{t-x, x} N_{t-x, x+1}=\mathrm{EP}_{t}-D_{t},
\end{aligned}
$$


where $D_{t}$ is the temporary deficit of the Employee's Pension System. Hence, the total social contribution tax rate is the sum of the basic pension and the employee's pension deficits, i.e. $\tau_{s t}=\tau_{s t}^{k n}+\tau_{s t}^{e}$.

The government also provides goods and services, denoted by $G_{t}$, which are assumed to be a fixed proportion of the output. To finance the public expenditures and the deficit of the public pension system, the government levies taxes on labor income $\left(T_{l t}=\tau_{l} w_{t} L_{t}\right)$, capital income $\left(T_{k t}=\tau_{k} r_{t} A_{t}\right)$, property $\left(T_{p t}=\tau_{p} A_{t}\right)$, bequest received $\left(T_{b t}=\tau_{b} B_{t}\right)$, and consumption $\left(T_{c t}=\tau_{c t} C_{t}\right)$. We assume the government runs a balanced budget in which consumption taxes finance the gap between public expenditures and all other tax revenues:

$$
T_{l t}+T_{k t}+T_{p t}+T_{b t}+T_{c t}=G_{t}+\left(1-\theta_{t}\right) \mathrm{BP}_{t}+D_{t} .
$$

\subsection{Equilibrium}

Given $\left\{\Gamma_{t}, \delta_{t}, \mathcal{L}_{t}, \mathcal{N}_{t}\right\}_{t=t_{0}}^{T}$, a recursive competitive equilibrium with transfers is a set of household policy functions $\left\{c_{i, x}, \ell_{i, x}, a_{i, x}, z\right\}_{x=x_{0}}^{\Omega}$, familial transfers $\left\{B e q_{i, x}\right\}_{x=x_{0}}^{\Omega-1}$ over $t \in\left\{t_{0}, \ldots, T\right\}$, government policy function $\left\{G_{t}, \tau_{k}, \tau_{l}, \tau_{p}, \tau_{b}, \ldots\right.$ $\left., \tau_{c t}, \tau_{s t}, \mu, \lambda(z), N_{b}, \psi(z), \vartheta_{t}\right\}_{t=t_{0}}^{T}$, and factor prices $\left\{r_{t}, w_{t}\right\}_{t=t_{0}}^{T}$ so that:

- Household policy function satisfies Eqs. 14, 15, and 16, given the factor prices, government policy functions, and familial transfers.

- The sum of inheritances given equals the sum of inheritances received:

$$
\sum_{x} B e q_{t-x, x} N_{t-x, x+1}=\sum_{x} q_{t-x, x} a_{t-x, x} N_{t-x, x+1}
$$

- Factor prices equal their marginal productivities, so that Eqs. 7 and 8 hold.

- The government's budget constraints (19), (20), and (21) are satisfied in each period.

- The stock of capital and effective labor input are given by

$$
\begin{aligned}
K_{t} & =\sum_{x=x_{0}}^{\Omega} a_{t-x, x} N_{t-x, x+1}, \\
L_{t} & =\sum_{x=x_{0}}^{\Omega} \epsilon_{x} \ell_{t-x, x} N_{t-x, x+1} .
\end{aligned}
$$

- The commodity market clears:

$$
Y_{t}=C_{t}+G_{t}+I_{t}
$$

where $C_{t}=\sum_{x=x_{0}}^{\Omega-1} c_{t-x, x} N_{t-x, x+1}$ is the aggregate consumption in year $t$. 


\section{Data, calibration, and matching}

\subsection{Demography}

Similar to Sanchez-Romero (2013), we use three demographic methods to reconstruct the Japanese population from 1850 up to now: the inverse projection, generalized inverse projection, and the stable population theory (Lee, 1985; Oeppen, 1993; Lotka, 1939). By combining these three demographic methods i) we derive an initial stable population that evolves consistently with the actual population data (see Fig. 1), ii) we derive age-specific fertility rates $\left(f_{i, x}\right)$ and conditional survival probabilities $\left(p_{i, x}\right)$ for each cohort that are used to reconstruct the monetary and time cost of childrearing $\left(\boldsymbol{\eta}_{i, x}\right.$, see Fig. 2), and iii) we derive the demographic relationships needed to calculate the familial transfers (i.e., parenthood, widowhood, number of offspring, number of surviving siblings, etc.). The demographic data from year 2010 onwards are based on mortality rates calculated using the Lee-Carter method (Lee and Carter, 1992) and age-specific fertility rates from Ogawa et al. (2010).

Data on population size, births, and deaths for the period 1872-2009 have been collected from the database "Historical Statistics in Japan", Statistics Bureau, Ministry of Internal Affairs and Communications. ${ }^{1}$ Life expectancy (at birth) data for the period 1947-2009 are downloaded from the Human Mortality Database (2012). Age-specific fertility rates (ASFR) from 1924 to 2004 have been taken from the Statistics Information Department, Minister's Secretariat, Ministry of Health, Labour and Welfare, while future age-specific fertility rates come from Ogawa et al. (2010).

Following Lee et al. (2000), the monetary and time cost of childrearing, depicted in Figures 2(a) and 2(b), are calculated as follows:

$$
\begin{aligned}
\eta_{i, x}^{c}-1 & =\sum_{u=x_{0}}^{x} \frac{s_{i, u} f_{i, u}}{s_{i, x}} s_{i+x-u, x-u} \theta_{x-u}^{c}, \\
\eta_{i, x}^{\ell} & =\sum_{u=x_{0}}^{x} \frac{s_{i, u} f_{i, u}}{s_{i, x}} s_{i+x-u, x-u} \theta_{x-u}^{\ell},
\end{aligned}
$$

where $\theta_{x}^{c}$ is the adult's consumption equivalence scale that equals 0.4 for children under age of 5 and increases linearly from age 5 to reach 1.0 at age $20 .^{2} \theta_{x}^{\ell}$ is the fraction of time devoted to taking care of a child of age $x$ that equals 1 at age 0 and decreases exponentially to reach 0 at age 20 . Since individuals leave their parents' home at age $x_{0}$, we set $\left\{\theta_{x}^{c}, \theta_{x}^{\ell}\right\}$ at zero for all $x>x_{0}$.

In Japan, the number of equivalent adult consumers supported by a household head peaks during the first half of the twentieth century reaching a value of 2 for the age group 35-45, which correspond to the baby-boom generation. This value implies that during the first half of the 20th century each household head spent supporting their offspring's consumption needs as much as on her/his own consumption. Similarly, the time devoted to childrearing significantly increased during the first half of the twentieth century for the age group 25-35. For instance, a representative household head had to spend $20 \%$ their available time

\footnotetext{
${ }^{1}$ The data can be downloaded from http://www.stat.go.jp/english/data/chouki/index.htm.

${ }^{2}$ This is the standard method used in the National Transfer Accounts project (NTA) (Mason and Lee, 2011). For a discussion of alternative methods, see Deaton (1997) and Lee (1980).
} 


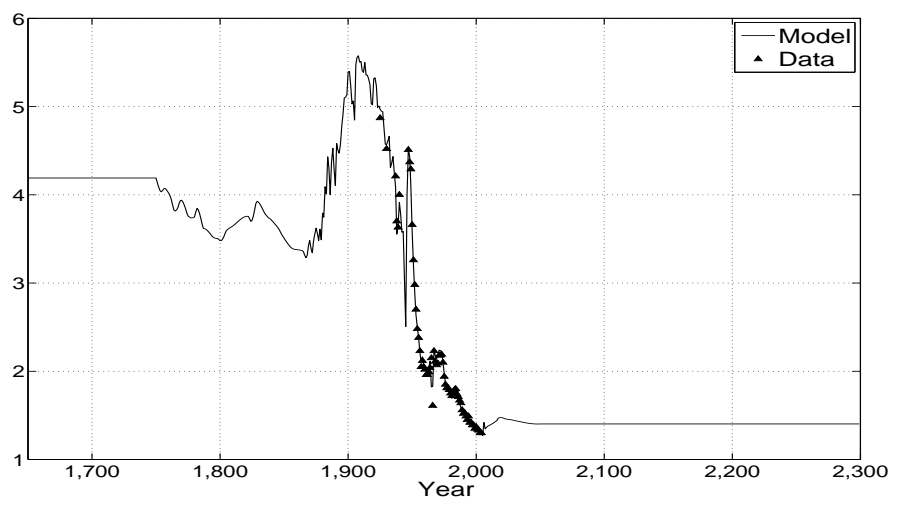

(a) Total fertility rate

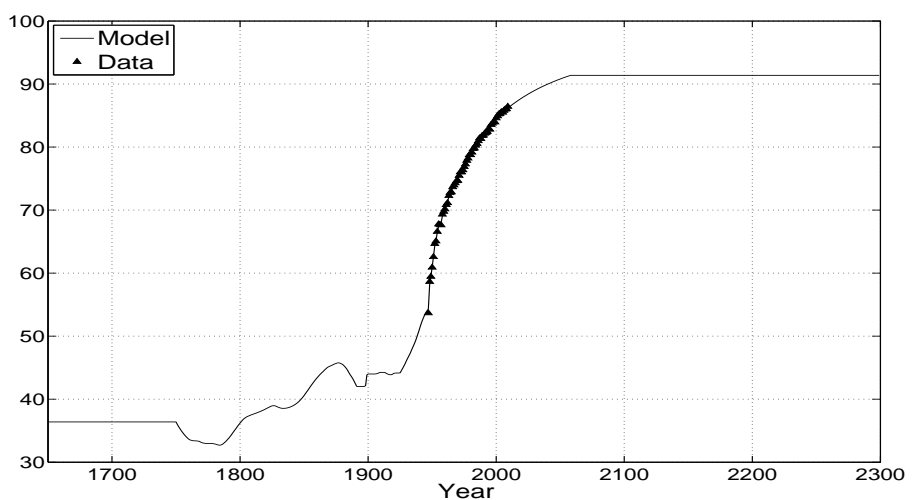

(b) Life expectancy at birth

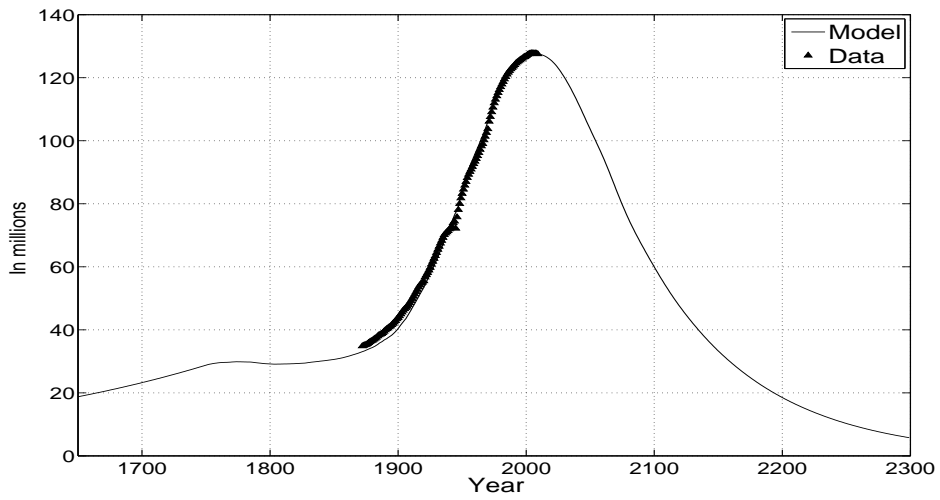

(c) Population size

Figure 1: Population reconstruction, Japan 1650-2300

Source: Authors' calculations based on information reported by the Historical Statistics in Japan, Statistics Bureau, Ministry of Internal Affairs and Communications; the Statistics Information Department, Minister's Secretariat, Ministry of Health, Labour and Welfare; and Ogawa et al. (2010). 


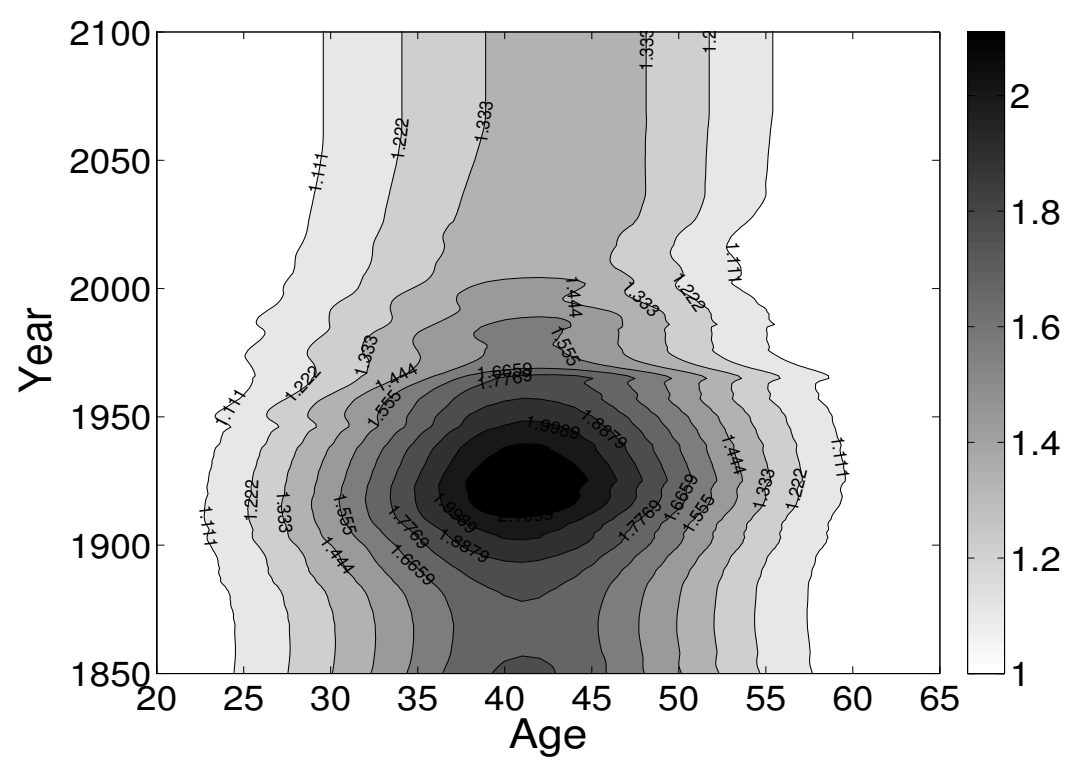

(a) Family size by household head, $\eta_{i, x}^{c}$

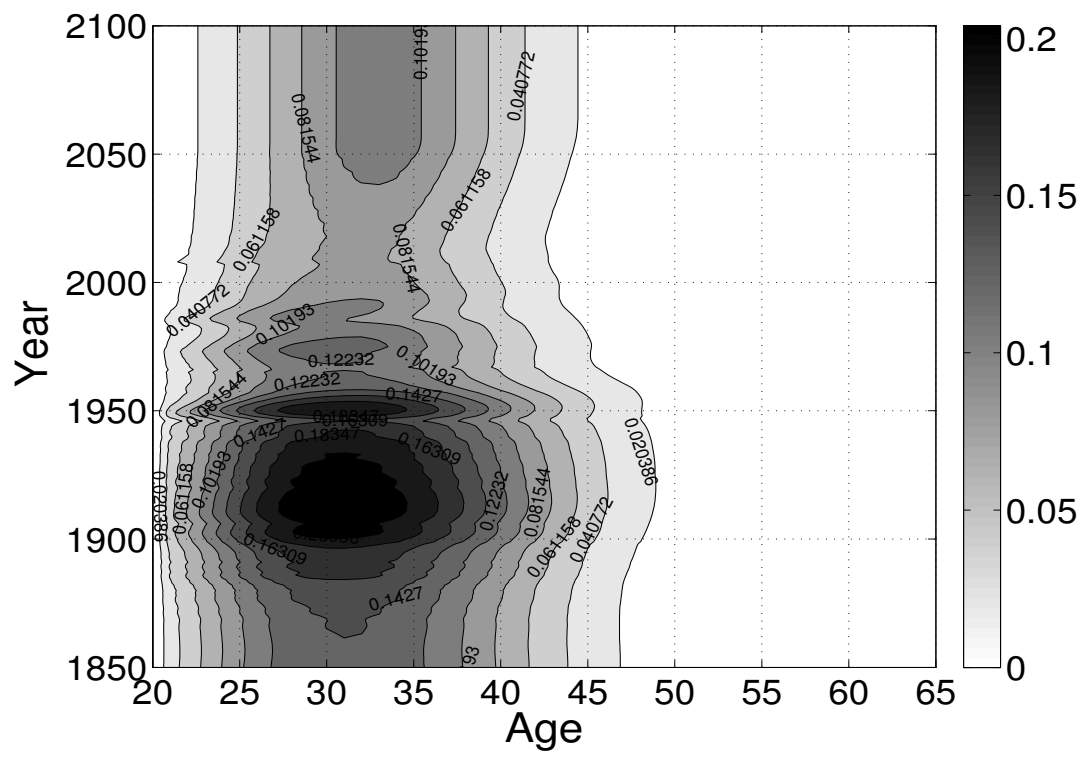

(b) Proportion of hours devoted to childrearing by household head, $\eta_{i, x}^{\ell}$

Figure 2: Contour plot of monetary and time cost of childrearing by household head $\left(\boldsymbol{\eta}_{i, x}\right)$, Japan 1850-2100.

Source: Authors' calculations based on estimates from the population reconstruction. 
caring for their offspring, which reduces the household head's potential labor income. After the 1950s, looking at Figure 2, we observe how the persistent decline in fertility freed up monetary and time resources for development. This process is part of the well-known first demographic dividend (Williamson, 2013; Sanchez-Romero, 2013; Kelley and Schmidt, 2005; Bloom and Williamson, 1998) that started in the 1950s and ended in the 1980s in Japan (Ogawa et al., 2011). In the long run, according to the mortality and fertility schedules depicted in Figure 1, household heads are expected to spent one-third of their own consumption on their offspring and an average of $10 \%$ of their time caring for their children.

Finally, in this article, by using the demographic information derived from the population reconstruction and Eqs (1)-(4), we estimate the average bequest received by an individual born in year $i$ at age $x$, which depends on the marriage status of parents and the marriage status of the receiver. Thus, we calculate four possible bequest profiles: a) bequest received at death of first parent, b) bequest received at death of second parent, c) bequest received at the simultaneous death of both parents, and d) bequest received at death of the spouse. The total amount of bequest received by age will depend not only on the demographics but also on the inheritance law and the number of assets held by each adult. Recall that the latter variable is endogenously derived from our CGE model.

\subsection{Economy}

We calibrate the model to the Japanese economy using i) SNA data from 18852010, published by the Department on National Accounts, Economic and Social Research Institute, Cabinet Office (2012), ii) consumption and labor income profiles for years 1984, 1994, and 2004 taken from Ogawa et al. (2011), and iii) the average bequest in year 2009 calculated from the Japanese Study on Aging and Retirement (JSTAR). ${ }^{3}$

For the sake of comparability with previous literature, we adopt a generalized version of the period utility function used by Braun et al. (2009) for Japan: ${ }^{4}$

$$
\begin{aligned}
& u\left(c_{i, x}, \ell_{i, x} ; \boldsymbol{\eta}_{i, x}\right) \\
& \quad=\left[\left(\left(\frac{c_{i, x}}{\eta_{i, x}^{c}}\right)^{\phi_{c} \eta_{i, x}^{c}}\left(1-\ell_{i, x}-\eta_{i, x}^{\ell}\right)^{1-\phi_{c}}\right)^{1-\frac{1}{\sigma}}-1\right] /\left(1-\frac{1}{\sigma}\right)
\end{aligned}
$$

as well as the recent utility from leaving bequest $a_{i, x}$ as conceptialized by Imrohoroglu and Kitao (2012):

$$
u^{B}\left(a_{i, x} ; \eta_{i, x}^{c}\right)=\psi_{1}\left[\left(\psi_{2}+(1-\gamma)\left(1-\tau_{b}\right) a_{i, x}\right)^{\phi_{c} \eta_{i, x}^{c}\left(1-\frac{1}{\sigma}\right)}-1\right] /\left(1-\frac{1}{\sigma}\right) .
$$

The parameter $\phi_{c}$ represents the utility weight on consumption, $\psi_{1}$ is the weight on the utility from bequeathing, and $\psi_{2}$ affects the curvature of the utility from leaving bequest. The parameters $\left\{\phi_{c}, \sigma\right\}$ were chosen so as to have an average

\footnotetext{
${ }^{3}$ JSTAR was conducted by the Research Institute of Economy, Trade and Industry (RIETI), Hitotsubashi University, and the University of Tokyo.

${ }^{4}$ The Frisch elasticity for labor supply is $\frac{1-\ell}{\ell} \frac{\sigma-\eta^{c} \phi_{c}(\sigma-1)}{\sigma+(1-\sigma)\left(1+\phi_{c}\left(\eta^{c}-1\right)\right.}$.
} 
Frisch elasticity on labor supply (both at the intensive and extensive margins) of 0.85 (Kuroda and Yamamoto, 2008), which is consistent with Rogerson and Wallenius (2013), and so as to replicate the capital-to-output ratio from 1885 to 2010 (see Figure $3(\mathrm{a})) .^{5}$ The per capita bequest by age is obtained from the JSTAR database (Ichimura et al., 2009). This survey contains information on the total amount of inheritance (bequest and gifts) received during the entire lifetime. Thus far, after the two first rounds of the survey, the sample of people who have received bequests in the period between 2007 and 2009 has been only 219 out of 3496 respondents. Since the sample size is small, we have smoothed the data using the Lowess method (see the solid gray curve in Figure 3(b)). We have opted for running three alternative scenarios with parameters $\left\{\psi_{1}, \phi_{c}, \sigma\right\}$ equal to $\{10,0.42,0.33\}$ : Scenario I (low bequest motive), $\{50,0.39,0.25\}$ Scenario II (medium bequest motive), and $\{400,0.36,0.18\}$ in Scenario III (high bequest motive). We believe that our scenarios cover the most likely bequest profile for year 2009 and, hence, from now on we consider these scenarios as equally likely.

Capital share $\alpha$ is set to 0.363 , based on Hayashi and Prescott (2002). The subjective discount factor is set to 0.99 (Imrohoroglu and Kitao, 2012; Braun et al., 2009; Hurd, 1989). Capital stock $(K)$, output $(Y)$, and consumption of fixed capital $(C F C)$ from 1885 to 2010 are derived from Department on National Accounts, Economic and Social Research Institute, Cabinet Office (2012). Using this information, we calculated that the average depreciation rate $(\delta)$ during this period is $5 \%$. We computed the labor-augmenting technological progress by applying the standard formula:

$$
\ln \Gamma_{t}=1 /(1-\alpha) \ln Y_{t} / N_{t}-\alpha /(1-\alpha) \ln K_{t} / N_{t}-\ln L_{t} / N_{t},
$$

where $L_{t}$ is quality-adjusted aggregate labor input and $Y_{t}$ is the GDP net of indirect taxes (Sun, 2006). To construct the quality-adjusted labor input series $L_{t}$, we combine the age-specific productivity index estimated by Braun et al. (2007), the average hours worked by age-group, and labour force by age group for the period 1968-2006 from the Statistics Bureau, Ministry of International Affairs and Communications. Figure 5 depicts the estimated labor-augmenting technological progress. It is assumed that $\Gamma_{t}$ grows from 1955 to 1968 at a constant 3\%, while before year 1955 and after 2006 we assume an annual growth of $1 \%$.

Government consumption-to-output ratio is set to $12 \%\left(G_{t} / Y_{t}\right)$, the average during the period of analysis. The capital income tax rate $\left(\tau_{k}\right)$, labor income tax rate $\left(\tau_{l}\right)$, property tax rate $\left(\tau_{p}\right)$, and the bequest tax rate $\left(\tau_{b}\right)$ are calculated using data from the OECD (2012). The main parametric components of the Japanese pension system, summarized in Table 1, have been obtained by combining information from Sakamoto (2005, 2009). For simplicity's sake, we assume that the automatic sustainability factor algorithm introduced in year

\footnotetext{
${ }^{5}$ Kuroda and Yamamoto (2008) find that the Frisch elasticity on the labor supply at the intensive and extensive margins ranges between 0.7 and 1.0 in Japan, when both males and females are combined.
} 


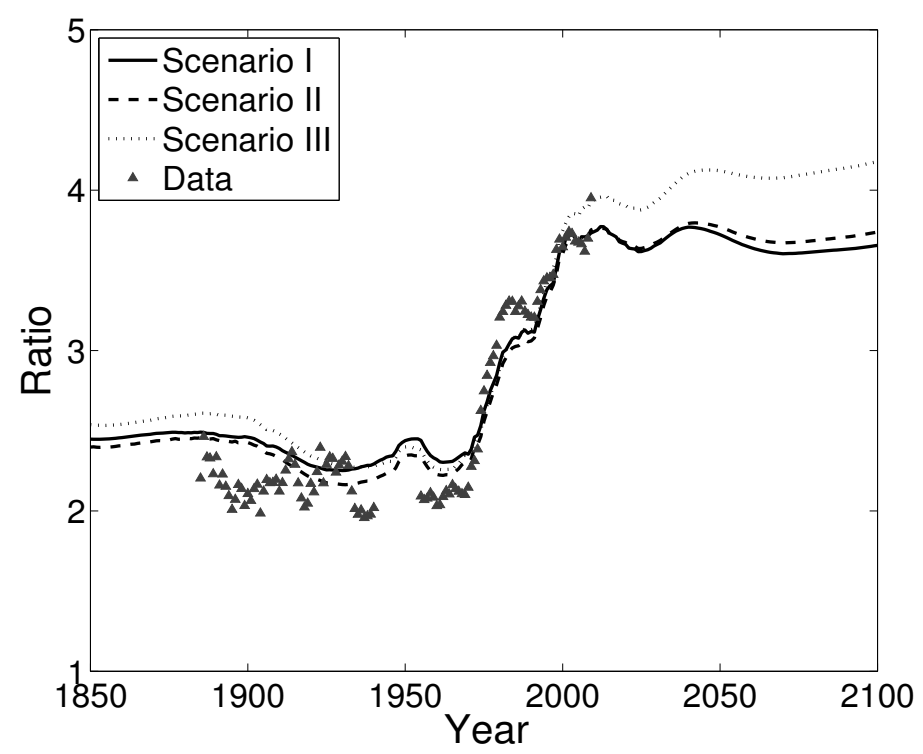

(a) Capital-to-output ratio, Japan 1850-2100

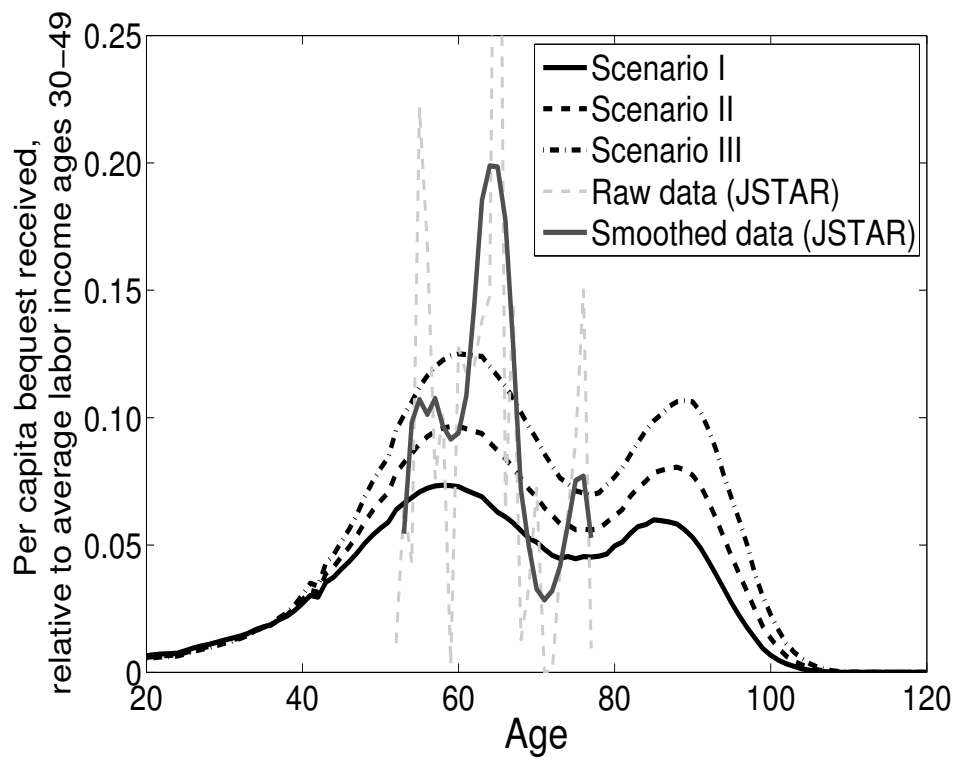

(b) Per capita bequest received, Japan 2009

Figure 3: Model performance, Japan 1850-2100

Source: Authors' calculations using Ichimura et al. (2009) (JSTAR) and information collected from the Department on National Accounts, Economic and Social Research Institute, Cabinet Office (2012). 


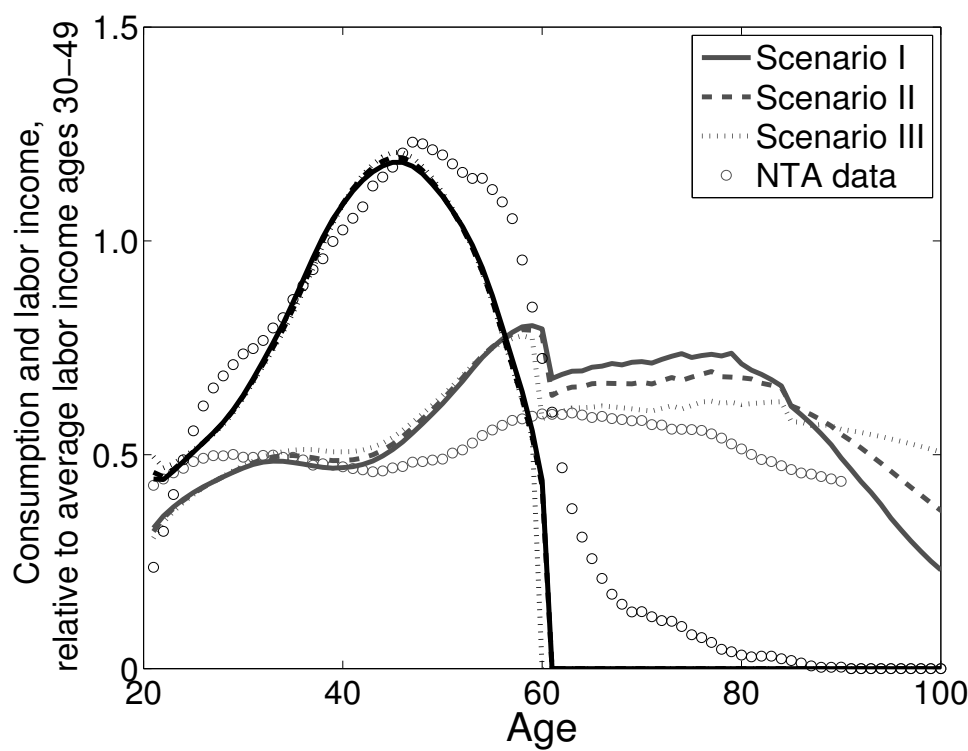

(a) Year 1984

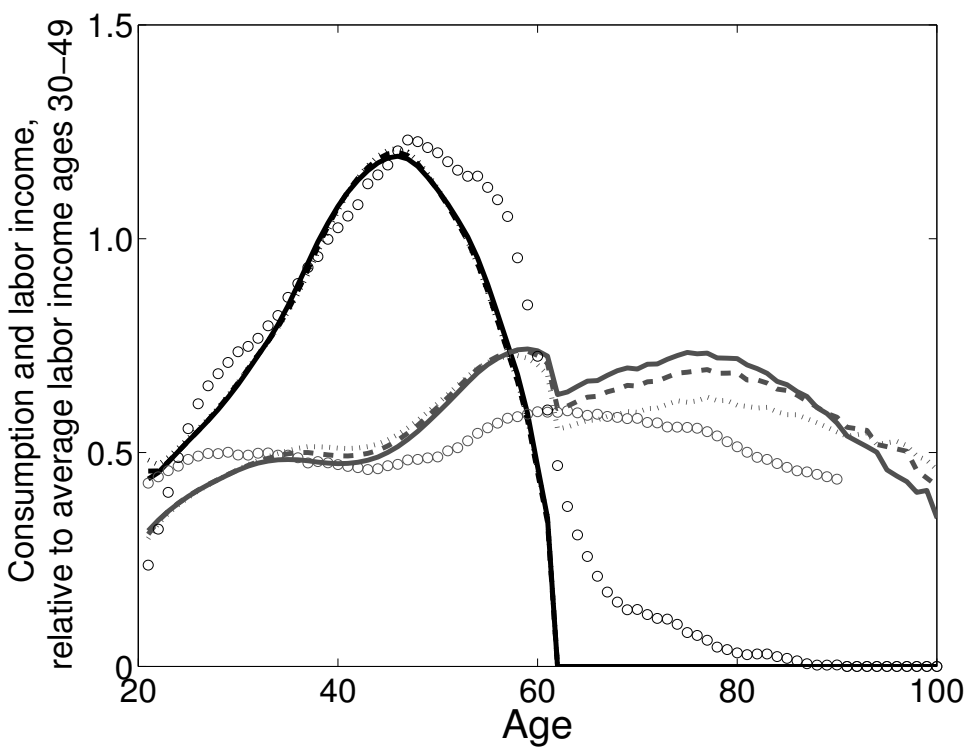

(b) Year 2004

Figure 4: Economic lifecycles: per capita consumption and labor income by age, Japan

Note: Labor income profiles are in black while consumption profiles are in gray color. 


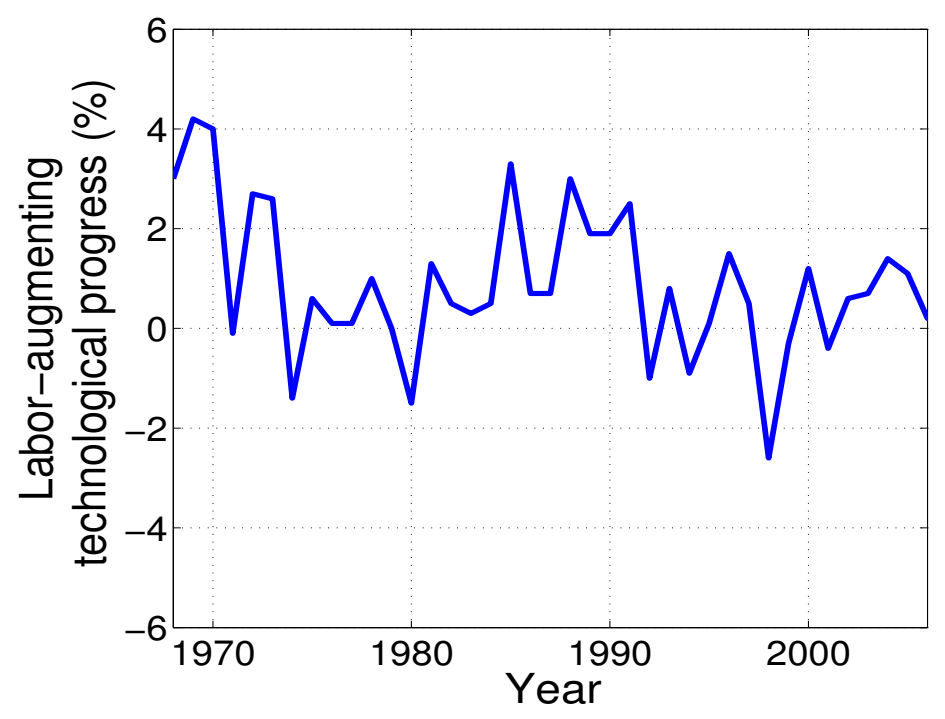

Figure 5: Labor-augmenting technological progress, Japan 1968-2006 Source: Authors' calculations

2004 is given by:

$$
\begin{aligned}
& \vartheta_{t}=\max \left(0.5, \vartheta_{t-1}\right) \\
& \cdot \begin{cases}\left(\frac{L_{t}}{L_{t-1}}\right) \cdot 0.997^{\frac{e_{t}(65)}{e_{t-1}(65)}-1} & \text { If }\left(\frac{L_{t}}{L_{t-1}}\right) \cdot 0.997^{\frac{e_{t}(65)}{e_{t-1}(65)}-1}<\frac{w_{t}}{w_{t-1}} \\
0 & \text { If }\left(\frac{L_{t}}{L_{t-1}}\right) \cdot 0.997^{\frac{e_{t}(65)}{e_{t-1}(65)}-1} \geq \frac{w_{t}}{w_{t-1}}\end{cases}
\end{aligned}
$$

where $e_{t}(65)$ is life expectancy from age 65 in year $t$. Notice that in order to avoid an ever decreasing sustainability factor due to a declining labor force, we introduce the assumption that $\vartheta$ cannot be smaller than 0.5. Furthermore, from year 2004 we introduce a maximum social contribution rate for the Employee's Pension Scheme $\left(\tau_{s, t}^{e}\right)$ starting at $13.58 \%$. Afterwards, the maximum contribution rate is assumed to increase $0.354 \%$ every year until 2018, reaching a maximum of $18.3 \%$.

Table 2 summarizes the main baseline model economy parameters.

\section{Estimation of the historical bequest}

In Section 3 we have shown that our model is capable of reproducing historical capital-to-output data as well as consumption, labor income, and bequest profiles for several years. Therefore, we are confident that our CGE model can provide a further insight into the historical evolution of the bequest to output ratio and the importance of bequests for the existing capital stock in Japan.

To the best of our knowledge, this is the first article using a CGE model that analyze the historical evolution of bequest in Japan. However, there are several studies that estimate bequests for the 1980s and 1990s (Shimono and Ishikawa, 2002; Campbell, 1997; Barthold and Ito, 1992; Dekle, 1989; Hayashi, 
Table 1: Key COMPONENTS OF the JAPANESE PENSION System

\begin{tabular}{|c|c|c|c|c|c|c|}
\hline \multirow{2}{*}{$\begin{array}{l}\text { Parametric } \\
\text { component }\end{array}$} & \multicolumn{3}{|c|}{ Basic pension } & \multicolumn{3}{|c|}{ Earning-related pension } \\
\hline & before 1994 & Reform 1994 & Reform 2004 & before 2000 & Reform 2000 & Reform 2004 \\
\hline$r_{a}$ & - & - & - & $0.7500 \%$ & $0.7125 \%$ & $0.7125 \%$ \\
\hline$\psi(z)$ & - & - & - & $r_{a} \cdot z$ & $r_{a} \cdot z$ & $r_{a} \cdot z$ \\
\hline$\lambda_{p}$ & $6 \%$ & $6 \%$ & $6 \%$ & - & - & - \\
\hline$\lambda_{r}$ & $8.4 \%$ & $8.4 \%$ & $8.4 \%$ & - & - & - \\
\hline$N_{b}$ & - & - & - & 40 & 40 & 40 \\
\hline$z_{n}$ & 65 & 65 & 65 & 65 & 65 & 65 \\
\hline$z_{e}$ & 60 & $\begin{array}{l}\text { one year } \\
\text { increase from } \\
\text { year } 2000 \\
\text { every three } \\
\text { years until age } \\
65\end{array}$ & $\begin{array}{l}\text { one year } \\
\text { increase from } \\
\text { year } 2000 \\
\text { every three } \\
\text { years until age } \\
65\end{array}$ & 60 & $\begin{array}{l}\text { one year } \\
\text { increase from } \\
\text { year } 2012 \\
\text { every three } \\
\text { years until age } \\
65\end{array}$ & $\begin{array}{l}\text { one year } \\
\text { increase from } \\
\text { year } 2012 \\
\text { every three } \\
\text { years until age } \\
65\end{array}$ \\
\hline$\mu$ & $18.33 \%$ & $18.33 \%$ & $18.33 \%$ & - & - & - \\
\hline$\vartheta$ & - & - & - & - & - & $\begin{array}{l}\text { Introduction } \\
\text { of the } \\
\text { sustainability } \\
\text { factor }\end{array}$ \\
\hline$\theta$ & 0.66 & 0.66 & 0.50 & - & - & - \\
\hline
\end{tabular}

Table 2: Model ECONOMY PARAMETERS

\begin{tabular}{lccc}
\hline \hline & Symbol & Value & Source \\
\cline { 2 - 4 } Household heads & & & \\
Elasticity of substitution & $\sigma$ & $\{0.33 ; 0.25 ; 0.18\}$ & \\
Weight on consumption & $\phi_{c}$ & $\{0.42 ; 0.39 ; 0.36\}$ & \\
Weight on bequest utility & $\psi_{1}$ & $\{10 ; 50 ; 400\}$ & \\
Curvature of bequest utility & $\psi_{2}$ & $0.01 \Gamma_{t}$ & \\
Subjective discount factor & $\beta$ & 0.99 & \\
Age at leaving parent's home & $x_{0}$ & 20 & \\
Maximum age & $\Omega$ & 120 & Japanese Civil Code \\
Employee social contribution share & $\varsigma$ & 0.50 & \\
Distribution of bequest & & $50 \%$ children-50\%spouse & Hayashi and Prescott $(2002)$, \\
& & & Chen et al. $(2007)$, \\
Technology & $\alpha$ & 0.363 & Braun et al. (2009) \\
Capital share & & & National accounts \\
& & & National accounts \\
Depreciation rate & $\Gamma_{t}$ & $5.00 \%$ & Braun et al. (2009) \\
Productivity & $\epsilon_{x}$ & & National accounts \\
Labor efficiency profile & & & OECD \\
Government & $\tau_{k}$ & 0.12 & OECD \\
Public consumption to output & $G / Y$ & 0.150 & OECD \\
Capital income tax rate & $\tau_{l}$ & 0.075 & OECD \\
Labor income tax rate & $\tau_{p}$ & 0.005 & \\
Property tax rate & & & \\
Bequest tax rate & $\tau_{b}$ & & \\
\hline
\end{tabular}


1986). In Japan, most of the studies state that bequests play a minor role in terms of explaining the existing national wealth during the period they analyzed (Campbell, 1997; Barthold and Ito, 1992; Dekle, 1989; Hayashi, 1986), except for Shimono and Ishikawa (2002) who estimate that bequests might account for 30 to 40 percent of the national wealth for the period 1986-1994. The results obtained by them, however, are overestimated due to the fact that they calculate total bequests by multiplying the average bequest left by a deceased male by the total population at risk, instead of multiplying by the deceased male population. If one used the latter variable, total bequests would turn out to be $8-13 \%$ of the national wealth. ${ }^{6}$ Nevertheless, even this result could be upward biased because the last age-group interval used for their calculation (age 65 and over) is too young for the Japanese population. ${ }^{7}$

Recently, using observed bequests and gifts tax data from France, Piketty (2011) showed that the inheritance to output ratio follow a pronounced Ushaped pattern during the twentieth century. Figure 6 shows that in Japan all simulated bequest to output ratios follow the same U-shaped pattern. The difference between our results and those of Piketty is due to the fact that he also includes gifts (inter-vivos transfers), which account on average for $50 \%$ of the total inheritance wealth transmission in France (Piketty, 2011, p. 1104). Therefore, our results suggest that the bequest to output ratio in Japan is very similar to that in France.

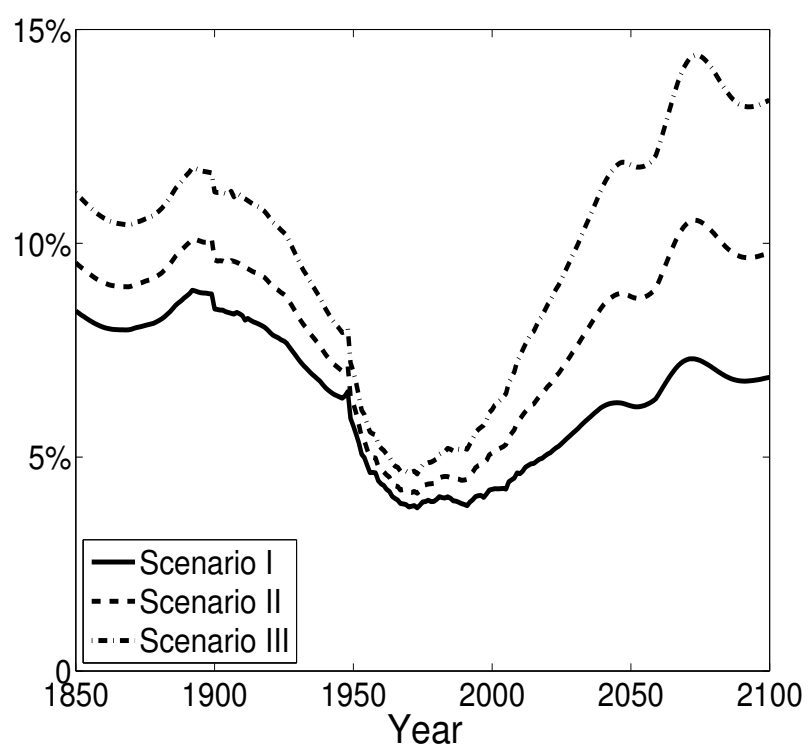

Figure 6: Annual bequest flow as a fraction of output, Japan 1850-2100

According to Piketty (2011), the observed U-shaped pattern is due to three

\footnotetext{
${ }^{6}$ Assuming a close economy, if the average capital-to-output ratio for the period 19861994 is 3.5 , a ratio of bequest to national wealth ratio of $8-13 \%$ should be equivalent to a bequest-to-output ratio of $30-47 \%$.

${ }^{7}$ Indeed, Simono and Ishikawa's age distribution implies that over 75 per cent of male household heads aged 65 and over die each year.
} 
components: i) the crude death rate $(C D R)$, ii) the aggregate wealth-output ratio $\left(K_{t} / Y_{t}\right)$, and iii) the ratio between the average wealth of the deceased adults and the average wealth of the living adults $\left(\mu_{t}\right){ }^{8}$ Table 3 shows the evolution of the bequest-to-output ratio decomposed by these three components. Unlike Piketty's study, in our case, the most important component explaining the U-shaped pattern is the evolution of the crude death rate. The capital-tooutput ratio and the ratio between the average wealth of the deceased and the average wealth of the living play a secondary role. In particular, the capitalto-output ratio in Japan was stable up to the 1950s, but then dramatically increased during the period 1950-1990. (See Figure 3(a)). Interestingly, in the 1950 s and 1960 s the average wealth of the deceased was double the average wealth of the living and, afterwards, progressively decline in all three scenarios.

Table 3: Decomposition of the Annual Bequest Flow AS A FRACTion OF OUTPUT, JAPAN 1850-2100

\begin{tabular}{|c|c|c|c|c|c|c|c|c|c|c|}
\hline \multirow[t]{2}{*}{ Year } & \multirow[t]{2}{*}{$\overline{C D D R_{t}(20+)}$} & \multicolumn{3}{|c|}{ Scenario I } & \multicolumn{3}{|c|}{ Scenario II } & \multicolumn{3}{|c|}{ Scenario III } \\
\hline & & $K_{t} / Y_{t}$ & $\mu_{t}$ & $B_{t} / Y_{t}$ & $K_{t} / Y_{t}$ & $\mu_{t}$ & $B_{t} / Y_{t}$ & $K_{t} / Y_{t}$ & $\mu_{t}$ & $B_{t} / Y_{t}$ \\
\hline 1850 & 0.024433 & 2.44 & 1.39 & $8.31 \%$ & 2.40 & 1.61 & $9.44 \%$ & 2.53 & 1.79 & $11.05 \%$ \\
\hline 1875 & 0.022051 & 2.49 & 1.46 & $8.00 \%$ & 2.45 & 1.67 & $9.03 \%$ & 2.58 & 1.84 & $10.47 \%$ \\
\hline 1900 & 0.022862 & 2.46 & 1.50 & $8.41 \%$ & 2.43 & 1.72 & $9.55 \%$ & 2.57 & 1.89 & $11.13 \%$ \\
\hline 1925 & 0.020317 & 2.25 & 1.69 & $7.71 \%$ & 2.19 & 1.98 & $8.82 \%$ & 2.29 & 2.21 & $10.26 \%$ \\
\hline 1950 & 0.012313 & 2.43 & 1.92 & $5.76 \%$ & 2.36 & 2.17 & $6.28 \%$ & 2.39 & 2.39 & $7.03 \%$ \\
\hline 1975 & 0.008102 & 2.62 & 1.87 & $3.97 \%$ & 2.57 & 2.09 & $4.35 \%$ & 2.60 & 2.30 & $4.84 \%$ \\
\hline 2000 & 0.009137 & 3.59 & 1.29 & $4.22 \%$ & 3.60 & 1.54 & $5.07 \%$ & 3.69 & 1.80 & $6.08 \%$ \\
\hline 2025 & 0.013275 & 3.62 & 1.10 & $5.28 \%$ & 3.64 & 1.45 & $7.01 \%$ & 3.82 & 1.80 & $9.10 \%$ \\
\hline 2050 & 0.016958 & 3.70 & 0.97 & $6.09 \%$ & 3.78 & 1.34 & $8.58 \%$ & 4.04 & 1.69 & $11.59 \%$ \\
\hline 2075 & 0.020905 & 3.61 & 0.95 & $7.16 \%$ & 3.68 & 1.35 & $10.37 \%$ & 3.99 & 1.70 & $14.20 \%$ \\
\hline 2100 & 0.020063 & 3.66 & 0.93 & $6.81 \%$ & 3.75 & 1.29 & $9.70 \%$ & 4.07 & 1.62 & $13.24 \%$ \\
\hline
\end{tabular}

Note: $C D R_{t}(20+)$ stands for the crude death rate from age 20 (i.e. the age at which individuals start accumulating assets), $K_{t} / Y_{t}$ is the capital to output ratio, $\mu_{t}$ is the ratio between the average wealth of the adult deceased and the average wealth of the living adults, and $B_{t} / Y_{t}$ is the bequest to output ratio.

The multiplication of the three components gives the annual bequest flow as a fraction of the output. Thereby, our simulations suggest that bequest represented between $4.2 \%$ and $6 \%$ of the output in year 2000 and that it will reach between $6.8 \%$ and $13.2 \%$ of the output by year 2100 .

To analyze the influence of bequests on the existing wealth in Japan, we extend the two competing definitions of the share of inheritance in aggregate wealth accumulation proposed by Kotlikoff and Summers (1981), Kotlikoff

${ }^{8}$ It is worth realizing that the formula introduced by Piketty (2011) is a pure accounting identity:

$$
\begin{aligned}
\frac{B_{t}}{Y_{t}} & =\frac{\sum_{x} q_{t-x, x} a_{t-x, x} N_{t-x, x+1}}{Y_{t}}=\frac{\sum_{x} q_{t-x, x} a_{t-x, x} N_{t-x, x+1}}{\sum_{x} a_{t-x, x} N_{t-x, x+1}} \frac{\sum_{x} a_{t-x, x} N_{t-x, x+1}}{Y_{t}} \\
& =\frac{\sum_{x} q_{t-x, x} N_{t-x, x+1}}{\sum_{x} N_{t-x, x+1}} \frac{\frac{\sum_{x} q_{t-x, x} a_{t-x, x} N_{t-x, x+1}}{\sum_{x} q_{t-x, x} N_{t-x, x+1}}}{\frac{\sum_{x} a_{t-x, x} N_{t-x, x+1}}{\sum_{x} N_{t-x, x+1}}} \frac{K_{t}}{Y_{t}}=C D R_{t}\left(x_{0}\right) \cdot \mu_{t} \cdot \frac{K_{t}}{Y_{t}} .
\end{aligned}
$$


(1988), and Modigliani $(1986,1988)$ to non-stable demographic structures. ${ }^{9}$ Recall that the difference between the two competing definitions stems from the capitalization of past bequests. Let the total wealth inherited up to age $x$ by an individual of cohort $i$ be:

$$
\begin{array}{ll}
\tilde{T}_{i, x}=\sum_{s=0}^{x}\left(\prod_{z=s}^{x} p_{i, z}\right) B e q_{i, s}, & \text { (Modigliani) } \\
T_{i, x} & =\sum_{s=0}^{x}\left(\prod_{z=s}^{x} R_{i, z}^{a} p_{i, z}\right) B e q_{i, s} .
\end{array}
$$

Eq. 32 stands for the value of the stream of bequests received up to age $x$ and not yet bequeathed, while Eq. 33 is the value of past bequests capitalized until age $x$ and not yet bequeathed. ${ }^{10}$ In a standard mortality schedule, total wealth inherited increases the younger the individual who receives the bequest is and the greater the difference between the age of receiving bequest and the age of giving bequest. Table 4 shows average ages of bequeathing (denoted by $\bar{D}$ ) and receiving bequest (denoted by $\bar{I}$ ) derived from our CGE model for the three scenarios. Since individuals who wish to give a bequest do not completely deplete their assets before reaching the maximum age, the difference between the average age of bequeathers and the average age of heirs is greater in Scenario III (22.7 years) and progressively declines as the strength of the bequest motive diminishes (22.2 years in Scenario II and 21.4 years in Scenario I). During the period 1850-2100, we can observe a continuous and parallel increase in both $\bar{D}$ and $\bar{I}$ of 28 years.

Adding the total inherited wealth across age we obtain the aggregate inherited wealth in year $t$ :

$$
\begin{array}{rlr}
\tilde{\boldsymbol{T}}_{t} & =\sum_{x=0}^{\Omega-1} \tilde{T}_{t-x, x} N_{t-x, x}, & \text { (Modigliani) } \\
\boldsymbol{T}_{t} & =\sum_{x=0}^{\Omega-1} T_{t-x, x} N_{t-x, x} & \text { (Kotlikoff) }
\end{array}
$$

Figure 7 shows our results for the non-capitalized and the capitalized bequest as a fraction of aggregate wealth for Japan from year 1850 to 2100. Applying the definition proposed by Modigliani $(1986,1988)$, we can see that the noncapitalized bequests may have been between $60-70 \%$ of the aggregate wealth during the second half of the 19th century (see Figure $7(\mathrm{a})$ ). Then, non-capitalized bequest progressively declined during the 20th century bottoming out around at $25 \%$ of the aggregate wealth. In the 21 st century, however, our simulations suggest that non-capitalized bequest will again increase up to $40-70 \%$ of the aggregate wealth. This result supports the hypothesis that bequest will become important for aggregate wealth accumulation in the twenty-first century (Piketty, 2011).

\footnotetext{
${ }^{9}$ In demography a stable population differs from a stationary population in that the latter has zero growth rate, while both are subject to unchanged fertility and mortality rates.

${ }^{10}$ If people die at age $D$, the number of years between the age at death and the year they received inheritance is $H$, the rate of return is $r$, and the economic growth rate is $g$, then Eqs. 32-33 are equivalent to those of Piketty (2011), Modigliani (1988), and Kotlikoff and Summers (1981).
} 


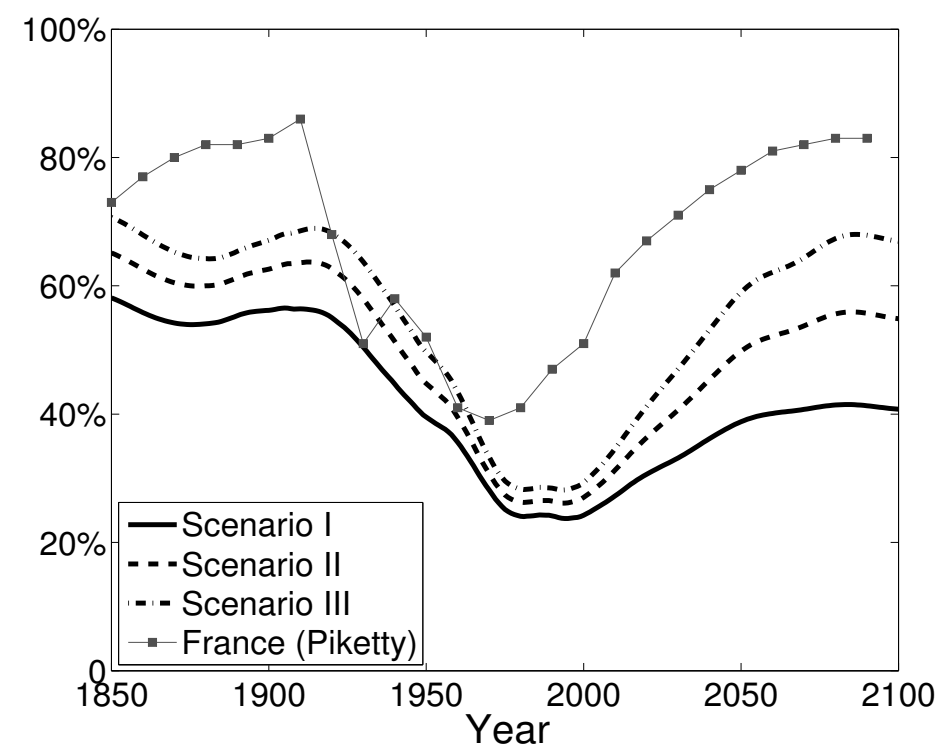

(a) Non-capitalized bequest as a fraction of aggregate private wealth, $\tilde{\boldsymbol{T}}_{t} / K_{t}$

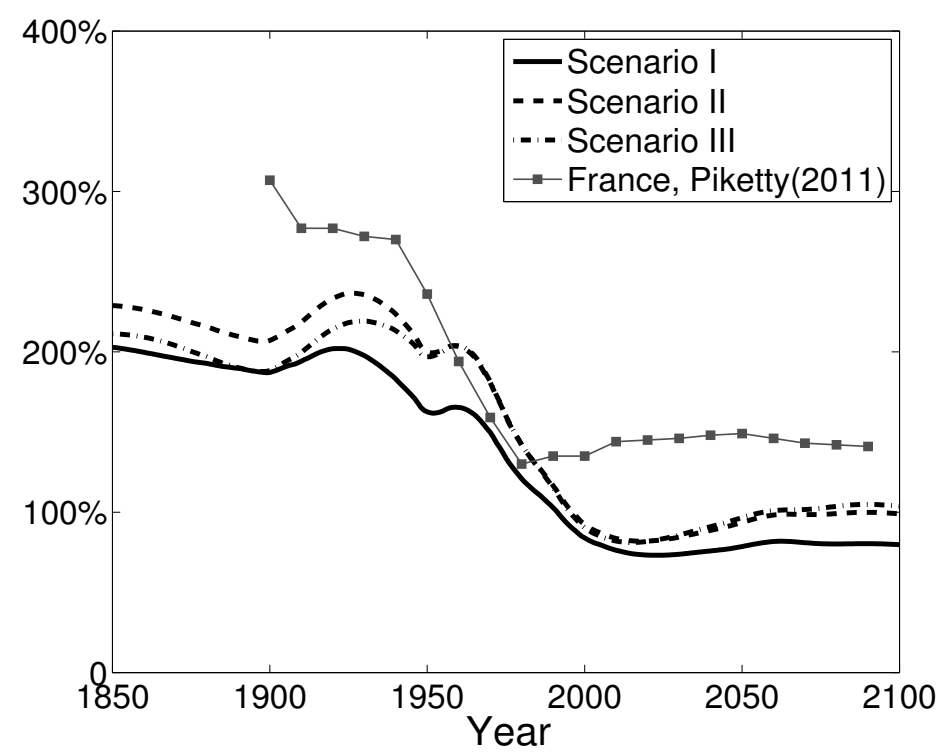

(b) Capitalized bequest as a fraction of aggregate private wealth, $\boldsymbol{T}_{t} / K_{t}$

Figure 7: Shares of capitalized and non-capitalized bequest in aggregate wealth accumulation, Japan 1850-2100 
Table 4: Average age of Bequeathing And AVERAge Age of HeIrs, JaPAN $1850-2100$

\begin{tabular}{|c|c|c|c|c|c|c|c|c|c|}
\hline \multirow[t]{2}{*}{ Year } & \multicolumn{3}{|c|}{ Scenario I } & \multicolumn{3}{|c|}{ Scenario II } & \multicolumn{3}{|c|}{ Scenario III } \\
\hline & $\bar{D}$ & $\bar{I}$ & $\bar{H}$ & $\bar{D}$ & $I$ & $\bar{H}$ & $\bar{D}$ & $I$ & $\bar{H}$ \\
\hline 1850 & 62.0 & 40.2 & 21.9 & 64.1 & 41.3 & 22.8 & 65.5 & 42.2 & 23.4 \\
\hline 1875 & 63.0 & 41.3 & 21.7 & 64.9 & 42.4 & 22.5 & 66.2 & 43.1 & 23.1 \\
\hline 1900 & 63.1 & 41.4 & 21.7 & 65.0 & 42.5 & 22.5 & 66.3 & 43.2 & 23.1 \\
\hline 1925 & 63.3 & 41.2 & 22.0 & 65.4 & 42.5 & 23.0 & 66.9 & 43.3 & 23.6 \\
\hline 1950 & 64.3 & 42.8 & 21.6 & 66.2 & 43.8 & 22.4 & 67.7 & 44.7 & 23.1 \\
\hline 1975 & 70.9 & 49.8 & 21.0 & 72.4 & 50.8 & 21.6 & 73.9 & 51.7 & 22.2 \\
\hline 2000 & 77.3 & 57.2 & 20.2 & 79.2 & 58.3 & 20.9 & 80.7 & 59.2 & 21.5 \\
\hline 2025 & 84.1 & 64.0 & 20.1 & 86.2 & 65.3 & 20.9 & 87.5 & 66.1 & 21.5 \\
\hline 2050 & 88.3 & 67.8 & 20.5 & 90.3 & 69.0 & 21.3 & 91.5 & 69.7 & 21.8 \\
\hline 2075 & 90.6 & 68.5 & 22.1 & 92.4 & 69.6 & 22.8 & 93.4 & 70.1 & 23.3 \\
\hline 2100 & 90.0 & 67.8 & 22.2 & 91.8 & 68.8 & 23.0 & 92.8 & 69.3 & 23.5 \\
\hline
\end{tabular}

Note: $\bar{D}$ stands for the average age of bequeathing, $\bar{I}$ is the average age of heirs, and $\bar{H}$ is the difference between $\bar{D}$ and $\bar{I}$.

The share of capitalized bequest to aggregate wealth was around 200-250\% in the last half of the 19th century and started to drop around the first quarter of the 20th century (see Figure $7(\mathrm{~b})$ ). Then, it bottomed out at values lower than $100 \%$ at the end of the 20th century, similar to the $80 \%$ reported by Kotlikoff and Summers (1981) for the U.S. in the 1960s-1970s. Interestingly, the size and shape of the decline in the share of capitalized bequest to aggregate wealth, that we obtained for Japan, also looks similar to that of France, although with a time lag probably due to the later entrance of Japan into the demographic transition.

Notice, however, that according to Figure 7(b) capitalized bequest will represent a much lower share of aggregate wealth in the 21st century, in contrast to the result obtained using Modigliani's definition. With these results we do not pretend to contribute to the Kotlikoff-Summers-Modigliani controversy. Instead, we take our results using $\tilde{\boldsymbol{T}}_{t}$ and $\boldsymbol{T}_{t}$ as likely minimum and maximum values for the share of bequests in aggregate wealth, which still suggest that bequest played an important role in the aggregate wealth accumulation during the 19th century. However, we cannot claim that this will be the case in the 21st century.

In the next section, we study in more detail how bequest is distributed over the lifecycle and whether bequest or labor income will play a major role in the future accumulation of assets.

\section{Per capita bequest and the capital stock}

\subsection{The distribution of per capita bequest}

The combination of the population reconstruction and the CGE model allows for computing per capita bequest profiles for each year in a realistic fashion. 
Here we explain how mortality and fertility changes the shape of the average bequest received along the lifecycle.

In our baseline model, we assume that bequests are shared between the surviving parent and the eligible siblings (i.e. adult siblings). In particular, based on the Japanese Civil Code, we assume that $50 \%$ of the bequest goes to the surviving parent and $50 \%$ is equally distributed among the adult siblings. In case that both parents die or the second parent dies, $100 \%$ of the bequest is inherited by the adult siblings. As already mentioned in Section 2.1, we distinguish four bequest profiles: 1) the bequest received after the death of the first parent, 2) bequest received after the death of the second parents, iii) bequest received to the simultaneous death of both parents, and iv) the bequest received from the spouse. ${ }^{11}$ Note that since we are analyzing a representative individual of each cohort, the per capita bequest received equals the sum of the four bequests profiles; otherwise the first three profiles should be mutually exclusive.

Table 5 shows the decomposition of the per capita bequest received from year 1850 to 2100 by bequeather. The dramatic demographic changes that occurred during the 20th century greatly influenced the family composition. For instance, before the year 1950, people could expect to receive the first bequest in their early 30 s after the death of a parent and, and another bequest approximately seven years later after the death of the remaining parent (see the first two columns 'average age' in Table 5). It was likely that a 40-year old individual would not have any parent alive. In addition, before year 1950 individuals would became widow/er in their mid-50s. After the year 1950, the per capita bequest profile shifts toward older ages due to the rapid increase in life expectancy. By year 2000, the death of the first parent was expected to occur when the child was 44 years old, and both parents were dead, on average, when individuals reached their mid-50s. Widowhood was postponed up to the early $70 \mathrm{~s}$, almost 20 years later than in the 1850s. By year 2100, and assuming that life expectancy does not increase from 2060 onwards (see Figure 3.1), the first bequest will be expected in the mid-50s and the death of the second parent will occur, on average, close to the child's retirement. Widowhood will happen in mid-80s.

Despite the fact that the total fertility rate (TFR) was between 3.5 and 4 before the year 1850, the average number of adult siblings at death of the first parent was 2 (see the first column 'average number of siblings' in Table 5). ${ }^{12}$ With the rise of fertility and the decline of mortality, the number of eligible siblings increase to over 3 from year 1925 to 1975 , substantially reducing the average per capita bequest received. However, from year 1975 to 2100 , the average number of adult siblings declines to 1.38. Not surprisingly, this value is close to the TFR since the risk of dying before age 50 will be very low.

Interestingly, by adding the average bequest received for the different bequest profiles reported in Table 5, we obtain the average per capita bequest relative to the average labor income between ages 30 and 49 (see Figure 8). This new measure is interesting because it is less sensitive to changes in the labor supply than output. Comparing Figure 6 to Figure 8 we can see that in all three scenarios per capita bequest relative to the average labor income for prime age

\footnotetext{
${ }^{11}$ In this paper, due to space constraints, we do not report the bequest arising from the simultaneous death of both parents because of its low probability.

${ }^{12} \mathrm{It}$ is worth noting that if there is a preference for giving the estate to a specific gender, there will be approximately one male and one female.
} 
Table 5: Decomposition of per CAPita Bequest Received (Baseline, 50\% CHILDREN-50\%SPOUSE), JAPAN 1850-2100

\begin{tabular}{|c|c|c|c|c|c|c|c|c|}
\hline & \multicolumn{6}{|c|}{ Bequest given by parents to children } & \multicolumn{2}{|c|}{ Bequest from spouse } \\
\hline & \multicolumn{3}{|c|}{ Death of first parent } & \multicolumn{3}{|c|}{ Death of second parent } & & \\
\hline & $\begin{array}{l}\text { Aver. } \\
\text { age }\end{array}$ & $\begin{array}{l}\text { Aver. } \\
\text { bequest } \\
\text { received }\end{array}$ & $\begin{array}{l}\text { Aver. } \\
\text { num. of } \\
\text { siblings }\end{array}$ & $\begin{array}{l}\text { Aver. } \\
\text { age }\end{array}$ & $\begin{array}{l}\text { Aver. } \\
\text { bequest } \\
\text { received }\end{array}$ & $\begin{array}{l}\text { Aver. } \\
\text { num. of } \\
\text { siblings }\end{array}$ & $\begin{array}{l}\text { Aver. } \\
\text { age }\end{array}$ & $\begin{array}{l}\text { Aver. } \\
\text { bequest } \\
\text { received }\end{array}$ \\
\hline \multicolumn{9}{|c|}{ Scenario I } \\
\hline 1850 & 30.5 & 0.020 & 2.00 & 37.8 & 0.052 & 1.71 & 53.7 & 0.024 \\
\hline 1875 & 31.3 & 0.020 & 2.07 & 38.7 & 0.049 & 1.84 & 55.8 & 0.023 \\
\hline 1900 & 31.4 & 0.020 & 2.12 & 38.7 & 0.050 & 1.83 & 55.9 & 0.024 \\
\hline 1925 & 31.2 & 0.018 & 2.82 & 38.5 & 0.044 & 2.30 & 55.8 & 0.022 \\
\hline 1950 & 32.3 & 0.015 & 3.31 & 39.6 & 0.033 & 2.97 & 58.9 & 0.017 \\
\hline 1975 & 37.7 & 0.011 & 3.06 & 47.3 & 0.020 & 2.88 & 66.2 & 0.012 \\
\hline 2000 & 44.2 & 0.012 & 2.30 & 55.4 & 0.017 & 2.56 & 72.6 & 0.012 \\
\hline 2025 & 51.0 & 0.013 & 1.88 & 62.0 & 0.020 & 1.84 & 79.7 & 0.014 \\
\hline 2050 & 54.5 & 0.013 & 1.41 & 66.3 & 0.021 & 1.55 & 83.4 & 0.013 \\
\hline 2075 & 55.3 & 0.014 & 1.44 & 66.2 & 0.025 & 1.43 & 85.9 & 0.015 \\
\hline 2100 & 54.3 & 0.014 & 1.38 & 65.0 & 0.022 & 1.38 & 85.6 & 0.014 \\
\hline \multicolumn{9}{|c|}{ Scenario II } \\
\hline 1850 & 31.4 & 0.018 & 2.01 & 39.5 & 0.059 & 1.69 & 54.8 & 0.023 \\
\hline 1875 & 32.2 & 0.019 & 2.09 & 40.3 & 0.055 & 1.83 & 56.8 & 0.022 \\
\hline 1900 & 32.3 & 0.020 & 2.13 & 40.3 & 0.057 & 1.81 & 57.0 & 0.023 \\
\hline 1925 & 32.2 & 0.017 & 2.82 & 40.2 & 0.051 & 2.26 & 57.0 & 0.020 \\
\hline 1950 & 33.1 & 0.014 & 3.34 & 41.3 & 0.035 & 2.96 & 59.5 & 0.015 \\
\hline 1975 & 38.5 & 0.011 & 3.06 & 48.7 & 0.021 & 2.90 & 67.0 & 0.011 \\
\hline 2000 & 45.4 & 0.012 & 2.35 & 56.7 & 0.021 & 2.61 & 73.9 & 0.013 \\
\hline 2025 & 52.7 & 0.015 & 1.91 & 63.2 & 0.027 & 1.85 & 81.4 & 0.015 \\
\hline 2050 & 56.3 & 0.015 & 1.44 & 67.2 & 0.031 & 1.53 & 85.2 & 0.015 \\
\hline 2075 & 57.1 & 0.017 & 1.45 & 67.1 & 0.038 & 1.42 & 87.7 & 0.018 \\
\hline 2100 & 55.9 & 0.017 & 1.38 & 65.9 & 0.034 & 1.38 & 87.2 & 0.017 \\
\hline \multicolumn{9}{|c|}{ Scenario III } \\
\hline 1850 & 32.2 & 0.022 & 2.02 & 40.6 & 0.081 & 1.65 & 55.2 & 0.027 \\
\hline 1875 & 32.9 & 0.022 & 2.10 & 41.4 & 0.074 & 1.81 & 57.1 & 0.026 \\
\hline 1900 & 32.9 & 0.023 & 2.12 & 41.4 & 0.076 & 1.80 & 57.5 & 0.027 \\
\hline 1925 & 33.0 & 0.020 & 2.80 & 41.5 & 0.069 & 2.22 & 57.5 & 0.024 \\
\hline 1950 & 33.9 & 0.015 & 3.36 & 42.7 & 0.046 & 2.91 & 59.8 & 0.017 \\
\hline 1975 & 39.2 & 0.012 & 3.08 & 50.0 & 0.028 & 2.91 & 67.7 & 0.012 \\
\hline 2000 & 46.5 & 0.015 & 2.46 & 57.6 & 0.030 & 2.63 & 75.1 & 0.015 \\
\hline 2025 & 53.9 & 0.019 & 1.90 & 64.0 & 0.041 & 1.87 & 82.7 & 0.020 \\
\hline 2050 & 57.6 & 0.020 & 1.50 & 67.8 & 0.048 & 1.53 & 86.4 & 0.021 \\
\hline 2075 & 58.1 & 0.023 & 1.45 & 67.6 & 0.059 & 1.41 & 88.7 & 0.024 \\
\hline 2100 & 57.0 & 0.022 & 1.38 & 66.4 & 0.051 & 1.38 & 88.2 & 0.024 \\
\hline
\end{tabular}

Note: Average bequest received is expressed in relative terms to the average labor income between ages $30-49$. 


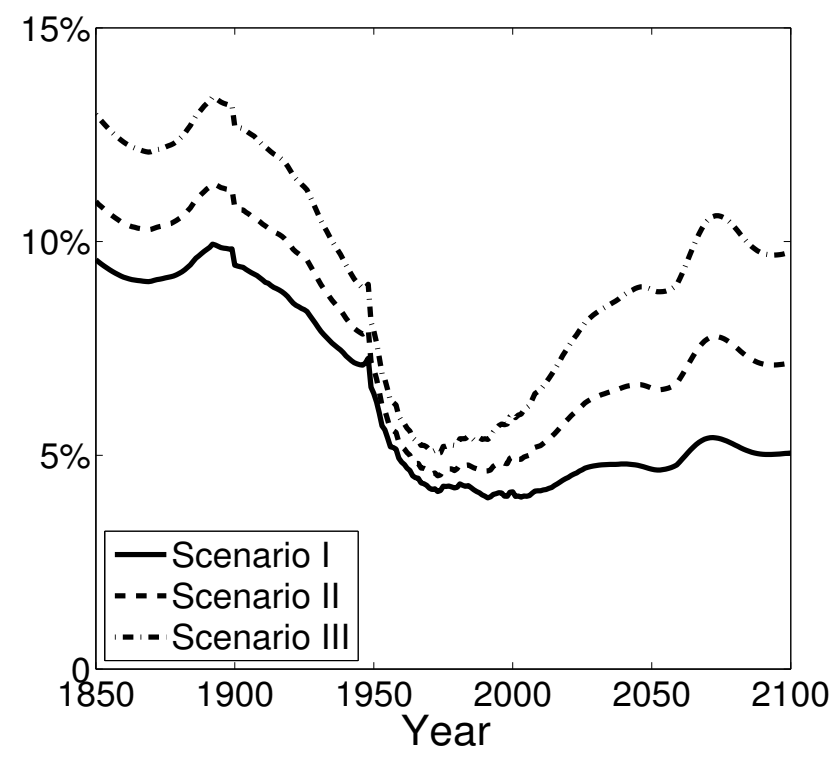

Figure 8: Average per capita bequest relative to average labor income (ages 30-49), Japan 1850-2100

workers does not increase as much as the bequest-to-output ratio during the twenty-first century. For instance, the Scenario I in Figure 8 suggests that labor income will continue playing a more important role for the well-being of individuals than bequest throughout the 21st century, while the opposite can be seen by looking at Figure 6 . Nevertheless, the difference between the two figures diminishes with the strength of the bequest motive. The explanation for the difference between figures 6 and 8 is simple. Changes in the population distribution have a bigger impact on the output than on the capital stock. Specifically, an increase in life expectancy followed by a decrease in fertility below replacement level (i.e. population aging) leads to a faster decline in output than in wealth and, as a result, the ratio of bequest to output rises. This is because, while the decline in the supply of labor affects both the output and the capital stock, individuals increase their savings in order to secure their consumption during retirement.

In sum, we believe that, in Japan, the importance of bequest and labor income in shaping the accumulation of assets during the 21st century will be almost the same as in the second half of the 20th century.

\subsection{Implications of the per capita bequest profile on the capital stock}

In the baseline model we have assumed, realistically, that $50 \%$ of the bequest goes to the surviving spouse and $50 \%$ to the children. Recall that the Japanese civil law presumes that one-half of the estate goes to the spouse and that each child receives an equal share of the remainder. In other countries, like the United States, there is no legal provision designating neither the number of heirs nor 
how much of a bequest is to be given. In Sweden, there is limited testamentary freedom so that the surviving spouse can freely use the deceased person's estate, but does not have the right to bequeath it, so that the estate finally goes to the children.

The large variety of bequest laws across countries generally reflects different social norms and specific historical and economic circumstances, which we abstract from. Taking this into consideration and given our model set up, it makes sense to receive the bequests early in life in order to reap the benefits of the inheritance during a longer period and, simultaneously, increase savings and the capital stock (see Eq. 33). To analyze the economic consequences of this policy option, we ran two additional counterfactuals in which the government announces that from year 2015 the shares of the inheritance given to the spouse and children will change. Specifically, the new shares are: i) $100 \%$ of the estate goes to the children and zero to the spouse (hereinafter labeled, counterfactual I) and ii) $100 \%$ of the state goes to the surviving spouse; and, in the case that there is no spouse, the inheritance goes to the children (hereinafter labeled, counterfactual II).

Figure 9 shows the distribution of the per capita bequest received and its impact on the capital-to-output ratio from 1985 to 2100 under the three different scenarios. The baseline scenarios are depicted in black, while the counterfactuals are depicted in dark gray (counterfactual I) and light gray (counterfactual II). At the first glance, we see that giving all the bequest to children (spouse) raises (diminishes) the capital-to-output ratio in all scenarios (see Figures 9(b), 9(d), $9(\mathrm{f}))$. This is due to the fact that the difference between the average age of bequeathers and the average age of receivers increases (decreases) (see Figures $9(\mathrm{a}), 9(\mathrm{c}), 9(\mathrm{~d}))$. In particular, in year 2015, while the average age of givers remain the same, the average age of receivers becomes 53.2 year (8.4 years less compared to the baseline) in Scenario I, 55.1 years ( 7.8 years less) in Scenario II, and 56.6 years (7.2 years less) in Scenario III. In contrast, when all the bequest is given to the surviving spouse, the average age of heirs increases 8.2 years (69.8 years old) in Scenario I, 7.5 year (70.4 years old) in Scenario II, and 6.9 years (70.7 years old) in Scenario III.

The result presented in this subsection suggests that with the observed increase in the labor force participation of women, and as long as actual households resemble our simulated households, an internal option for boosting the stock of capital, in order to cope with the rapid population aging, is to introduce a policy that transfers all the estate to children.

\section{Conclusion}

In this article we have implemented a general equilibrium model with realistic demography to estimate the historical evolution of bequest during the period 1850-2100.

Our simulation results suggest that bequest represented between 8 and 11 percent of the output in the second half of the 19th century. We showed how the rapid increase in population was accompanied with rapid changes in the household composition and a progressive decline in the share of bequest in output until the 1970s. By year 2000, the bequest-to-output ratio represented between $4 \%$ and $6 \%$ of the output. However, the rapid aging of the Japanese population 

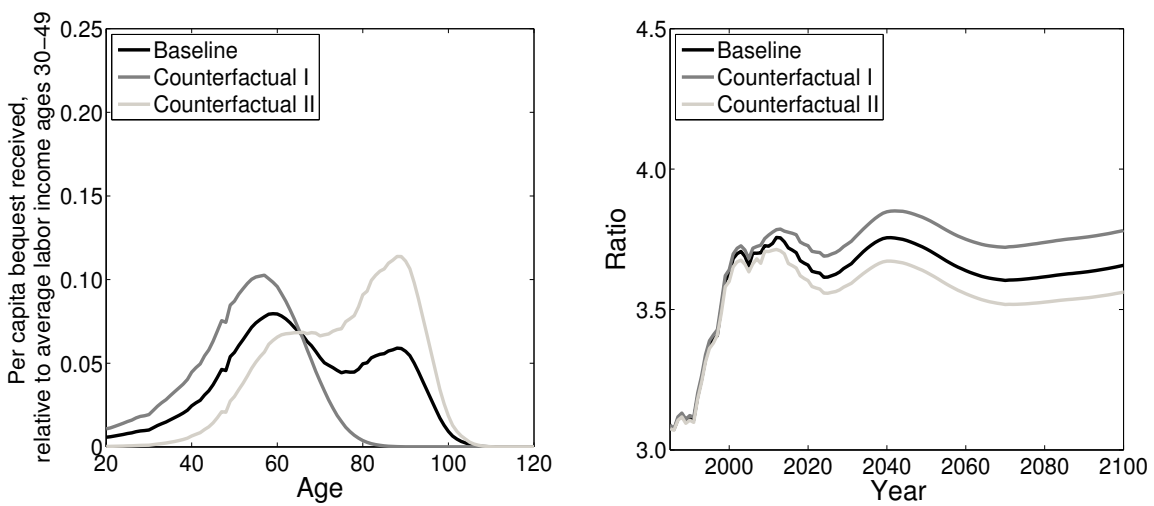

(a) Scenario I. Per capita bequest received, Japan 2015

(b) Scenario I. Capital-to-output ratio, Japan $1985-2100$
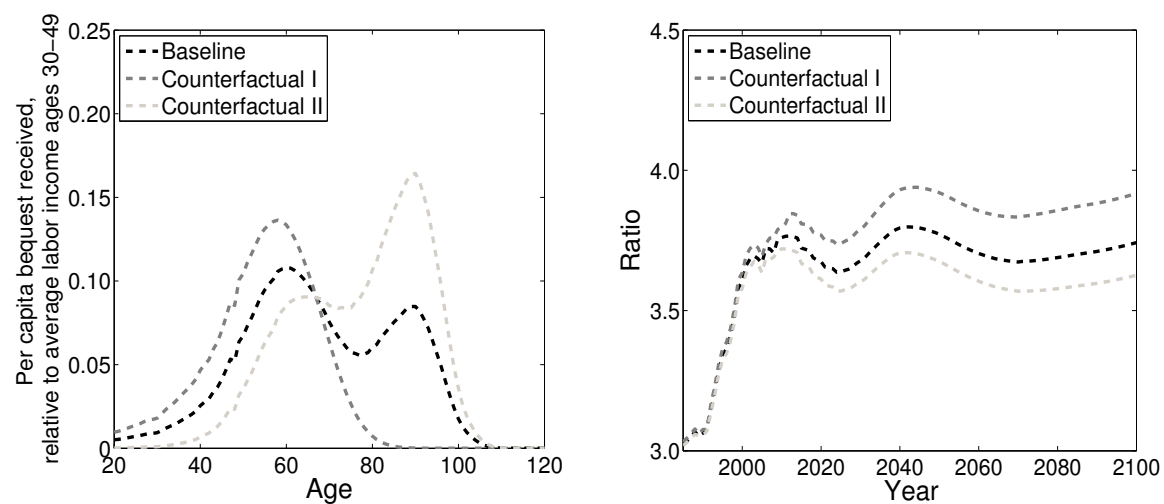

(c) Scenario II. Per capita bequest received, Japan 2015

(d) Scenario II. Capital-to-output ratio, Japan 1985-2100
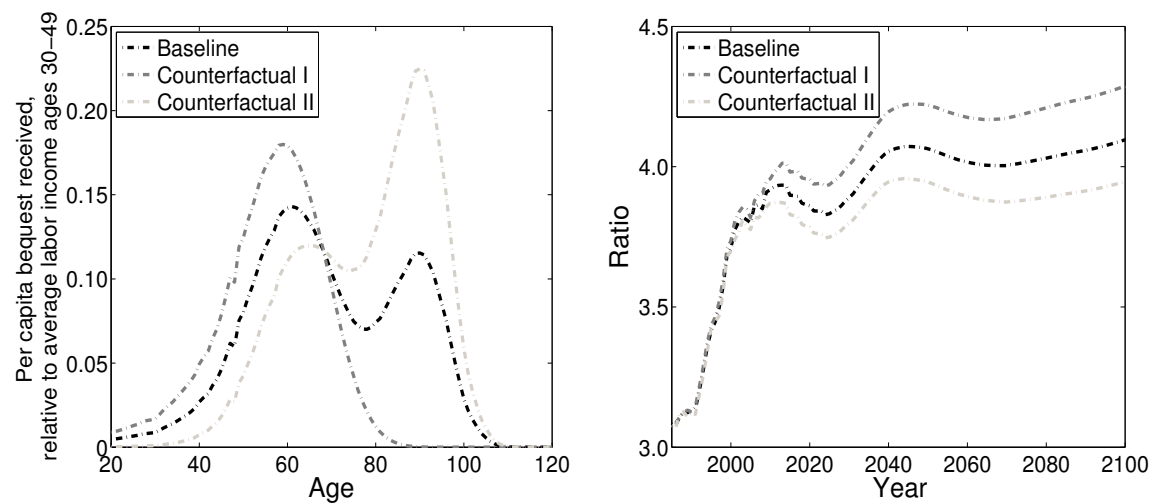

(e) Scenario III. Per capita bequest received, (f) Scenario III. Capital-to-output ratio, Japan 2015

Japan 1985-2100

Figure 9: The impact of bequest distribution on the capital-to-output ratio and per capita bequest received, Japan 1985-2100 
will raise the annual bequest flow as a fraction of output up to between $7 \%$ and $13 \%$.

Our historical pattern of the bequest-to-output ratio supports the result presented by Piketty (2011) for France. Nevertheless, we show that the most important variable explaining the U-shaped pattern in Japan is the crude death rate, rather than the evolution of the capital-to-output ratio or the ratio between the average wealth of the deceased and the average wealth of the living.

At the individual level, the recovery of the bequest-to-output ratio up to levels similar to those in the 19th century do not necessarily imply that bequests will become relatively more important than labor income (and thus human capital) in the accumulation of wealth.

\section{References}

Barthold, T. B., Ito, T., 1992. Bequest taxes and accumulation of household wealth: U.S. - Japan comparison. In Takatoshi, I. and Kruger, A. O. (eds) The Political Economy of Tax Reform. University of Chicago Press, pp. 235290.

Bloom, D., Williamson, J. G., 1998. Demographic transitions and economic miracles in emerging Asia. World Bank Economic Review 12 (3), 419-455.

Braun, A. R., Ikeda, D., Joines, D. H., 2009. The saving rate in Japan: Why it has fallen and why it will remain low. International Economic Review 50 (1), 291-321.

Braun, A. R., Ikeda, D., Joines, D. H., 2007. Saving and interest rates in Japan: Why they have fallen and why they will remain low. CIRJE Working Paper F-535, University of Tokyo.

Campbell, D. W., 1997. Transfer and life-cycle wealth in Japan: 1974-1984. The Japanese Economic Review 48 (4), 410-423.

Chen, K., Imrohoroglu, A., Imrohoroglu, S., 2007. The Japanese saving rate between 1960 and 2000:productivity, policy changes, and demographics. Economic Theory 32 (1), 87-104.

Deaton, A., 1997. The Analysis of Household Surveys: A Macroeconometric Approach to Development Policy. Baltimore and London: World Bank.

Dekle, R., 1989. The unimportance of intergenerational transfers in Japan. Japan and the World Economy 1 (4), 403-413.

Department of National Accounts, Economic and Social Research Institute, Cabinet Office, 2012. Annual Report on National Accounts, Tokyo: Media Land Co. Ltd.

Gruber, J., Wise, D. A. (eds.), 1999. Social Security and Retirement Around the World. National Bureau of Economic Research.

Gruber, J., Wise, D. A. (eds.), 2004. Social Security and Retirement Around the World: Micro-Estimation. University of Chicago Press. 
Gruber, J., Wise, D. A. (eds.), 2007. Social Security Programs and Retirement Around the World: Fiscal Implications. National Bureau of Economic Research.

Hayashi, F., 1986. Why is Japan's saving rate so apparently high?. In Fisher, S. (ed) NBER Macroeconomic Annual, MIT Press, 147-210.

Hayashi, F., Prescott, E. C., 2002. The 1990s in Japan: a lost decade. Review of Economic Dynamics 5 (1), 206-235.

Heckman, J., MaCurdy, T., 1980. A life cycle model of female labor supply. Review of Economic Studies 47 (1), 47-74.

Heckman, J., MaCurdy, T., 1982. Corrigendum on a life cycle model of female labour supply. Review of Economic Studies 49 (4), 659-660.

Human Mortality Database, 2012. University of California, Berkeley (USA), and Max Planck Institute for Demography Research (Germany). Available at www.mortality.org or www.humanmortality.de (data download in October 2012).

Hurd, M. D., 1989. Mortality risk and bequests. Econometrica 57 (4), 779-813.

Ichimura, H., Hashimoto, H., Shimizutani, S., 2009. JSTAR First Results: 2009 Report. RIETI Discussion Paper Series 09-E-047.

Imrohoroglu, S., Kitao, S., 2012. Social security reforms: Benefit claiming, labor force participation, and long-run sustainability. American Economic Journal: Macroeconomics 4 (3), 96-127.

Japan Statistical Association, 2006. Historical Statistics of Japan, New Edition, Vol. 1. Tokyo: Japan Statistical Association.

Kelley, A. C., Schmidt, R. M., 2005. Evolution of recent economic-demographic modeling: a synthesis. Journal of Population Economics 18 (2), 275-300.

Kotlikoff, L. J., Summers, L. H.,1981. The role of intergenerational transfers in aggregate capital accumulation. Journal of Political Economy 89 (4), 706-732.

Kotlikoff, L. J., 1988. Intergenerational transfers and savings. The Journal of Economic Perspectives 2 (2), 41-58.

Kuroda, S., Yamamoto, I., 2008. Estimating Frisch labor supply elasticity in Japan. Journal of The Japanese and International Economies (22), 566-585.

Lee, R. D., 1980. Age structure, intergenerational transfers and economic growth: an overview. In G. Tapinos (ed), Revue Economique, special issue on economic demography 31 (6), pp 1129-1156.

Lee, R. D., 1985. Inverse projection and back projection: A critical appraisal, and comparative results for England, 1539 to 1871. Population Studies 39, 233-248.

Lee, R. D., Carter, L., 1992. Modeling and forecasting U.S. mortality. Journal of the American Statistical Association 87(419), 659-671. 
Lee, R. D., Mason, A., Miller, T., 2000. Life cycle saving and the demographic transition: The case of Taiwan. Population and Development Review 26, 194 219.

Leslie, P. H., 1945. On the use of matrices in certain population dynamics. Biometrika 33, 183-212.

Lotka, A. J., 1939. Theorie Analytique des Associations Biologiques. Part II. Analyse Demographique avec Application Particuliere a l'Espece Humaine. Number 780. Hermann et Cie, Paris.

Mason, A., Lee, R. D., 2011. Introducing age into national accounts. In: Lee R.D., Mason A. (eds) Population Aging and the Generational Economy: A Global Perspective. Edward Elgar Publishing, Cheltenham, UK, pp. 55-78.

Modigliani, F., 1986. Life cycle, individual thrift and the wealth of nations. American Economic Review 76 (3), 297-313.

Modigliani, F., 1988. The role of intergenerational transfers and life cycle saving in the accumulation of wealth. Journal of Economic Perspectives 2 (2), 15-40.

OECD, 2012. Revenue Statistics. OECD Publishing.

Oeppen, J., 1993. Back projection and inverse projection: Members of a wider class of constrained projection models. Population Studies 47, 245-267.

Ogawa, N., Kondo, M., Matsukura, R., Tamura, M., Mason, A., Tuljapurkar, S., and Li, N., 2010. Cost Analysis on Aging Population and Low Birth Rate Based on NTA system. Nihon University Population Research Institute, Tokyo.

Ogawa, N., Matsukura, R., and Chawla, A., 2011. The elderly as latent assets in aging Japan. In: Lee R.D., Mason A. (eds) Population Aging and the Generational Economy: A Global Perspective. Edward Elgar Publishing, Cheltenham, UK, pp. 475-487.

Piketty, T., 2011. On the long-run evolution of inheritance: France 1820-2050. Working Paper, PSE 2010.

Piketty, T., 2011. On the long-run evolution of inheritance: France 1820-2050. The Quarterly Journal of Economics 126 (3), 1071-1131.

Preston, S. H., Heuveline, P., Guillot, M., 2002. Demography: Measuring and Modeling Population Processes. Blackwell Publishers Inc., Massachusetts.

Rogerson, R., Wallenius, J., 2013. Nonconvexities, retirement, and the elasticity of labor supply. American Economic Review 103 (4), 1445-1462.

Sakamoto, J., 2005. Japan's pension reform. SP Discussion paper No. 0541 of the World Bank.

Sakamoto, J., 2009. Demographic aging and Japan's public pension system. NRI Financial Research Paper "lakyara" No. 54.

Sanchez-Romero, M., 2013. The role of demography on per capita output growth and saving rates. Journal of Population Economics 26, 1347-1377. 
Sanchez-Romero, M., Sambt, J., Prskawetz, A., 2013. Quantifying the role of alternative pension reforms on the Austrian economy. Labour Economics 22, 94-114.

Shimono, K., 1991. Shisan kakusano keizai bunseki (An economic analysis of asset disparity), Tokyo: Nagoya Daigaku Shuppankai.

Shimono, K., Ishikawa, M., 2002. Estimating the size of bequests in Japan: 1986-1994. International Economic Journal 16 (3), 1-21.

Sun, C. H., 2006. Imperfect competition, economic miracle, and manufacturing productivity growth: empirical evidence from Taiwan. Atlantic Economic Journal 34, 341-359.

Williamson, J. G., 2013. Demographic dividends revisited. Asian Development Review 30 (2), 1-25.

Yaari, M., 1965. Uncertain lifetime, life insurance, and the theory of the consumer. Review of the Economic Studies 5 (3), 304-317. 